\title{
LA TORRE DE AUGUSTO EN LA CAMPA TORRES (GIJÓN, ASTURIAS). LAS ANTIGUAS EXCAVACIONES Y EL EPÍGRAFE DE CALPURNIO PISÓN
}

\author{
POR \\ CARMEN FERNÁNDEZ OCHOA \\ Universidad Autónoma de Madrid \\ ÁNGEL MORILLO CERDÁN \\ Universidad de León \\ ÁNGEL VILLA VALDÉS \\ Consejería de Cultura. Principado de Asturias
}

\section{RESUMEN}

Partiendo del análisis exhaustivo de la documentación historiográfica y del estudio arqueoarquitectónico de los restos arqueológicos exhumados en los siglos XVIII y XIX, hoy en día destruidos, planteamos la hipótesis de que en la Campa Torres se erigió en época augustea una gran torre con función de faro, que señalaba el acceso a la bahía de Gijón. Dicho monumento, del que procede la lapida calpurniana datada en el 9-10 d. C. (CIL II, 2703), no puede de ninguna manera interpretarse como una de las famosas Aras Sestianas. Con un carácter claramente simbólico, el faro constituiría un hito señalizador en el paisaje de una región militarizada y recientemente conquistada, además de desempeñar un claro papel de apoyo a la navegación cantábrica, al indicar la entrada al mejor puerto astur.

\section{SUMMARY}

Through the historiographic data and the architectonic and archaeologic study of the Roman remains found during the $18^{\text {th }}$ and $19^{\text {th }}$ Centuries, today disappeared, we present here an hypothesis about the Augustean construction of a big tower in Campa Torres. This would be identified as a lighthouse controlling the entrance of the Gijón's bay. The commemorative stone of Cn. Calpurnius Piso (CIL II, 2703), dated on 9-10 AD, was founded in this building. We cannot accept the identification of this monument as one of the wellknown Arae Sestianae. This light-house, with a symbolic character as well a purpose of informing to the mariners the access of the harbour, would be erected in a militarized region recently conquered.

PALABRAS CLAVE: Historiografía; Asturia; puerto; faro romano; lápida; Aras Sestianas; ejército romano.

KEY WORDS: Historiography; Asturia; port; light-house; commemorative stone; Arae Sestianae; Roman Army.

\section{INTRODUCCIÓN}

Un conocido biólogo, el profesor Krefs, decía que investigar es «ver lo que otros ven y pensar lo que no han pensado». Esta frase, aparentemente sencilla, encierra una gran sabiduría que resume una actitud imprescindible para hacer avanzar la ciencia $y$, en nuestro caso, refleja nítidamente el objetivo de esta aportación. En ella trataremos de proponer una interpretación original sobre los restos de las edificaciones documentadas en el castro de Campa Torres (Gijón) por el arquitecto Manuel Reguera quien, a instancias de Jovellanos, realizó un sondeo en este yacimiento en 1783, actuación que constituye la primera intervención arqueológica en el ámbito del concejo de Gijón (Fernández Ochoa, 2002: 41).

La intención de Jovellanos era descubrir el lugar exacto de procedencia de una inscripción dedicada a Augusto conocida ya desde el siglo XVI (CIL II 2703; ERA n ${ }^{\circ}$ 12) ${ }^{1}$ (fig. 1), que los eruditos venían considerando como una de las tres aras consagradas a Augusto en algún lugar de la costa del noroeste peninsular, denominadas genéricamente «Aras Sestianas» por haber sido erigidas, según afirman las fuentes textuales, por L. Sestius Quirinalis. Desde

${ }^{1}$ Es un gran bloque de mármol de tonos amarillo y gris, de $1,62 \mathrm{~m}$. de longitud por $0,80 \mathrm{~m}$. de altura y $0,50 \mathrm{~m}$. de grosor, que pesa $2.250 \mathrm{~kg}$. aproximadamente. Presenta una inscripción de cinco renglones en grandes letras capitales cuadradas. El cuarto renglón y parte del quinto han sido borrados. $\mathrm{Su}$ transcripción es la siguiente:

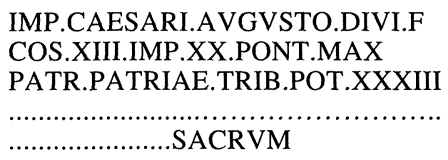

"Al emperador Cesar Augusto, hijo del Divino (Cesar) tres veces cónsul, emperador con veinte salutaciones imperiales, pontífice máximo, padre de la patria, treinta veces investido con la potestad tribunicia (Cneo Calpurnio Pisón, hijo de Cneo, legado propretor) consagró este monumento».

De acuerdo con esta inscripción, el altar habría sido levantado en el año 9-10 d. C. por el legado de la provincia citerior, Cneo Calpurnio Pisón, castigado por Tiberio con la damnatio memoriae al ser acusado de traición por su posición política. Por este motivo el nombre del dedicante habría sido borrado de la inscripción (Syme, 1969: 129-132). 


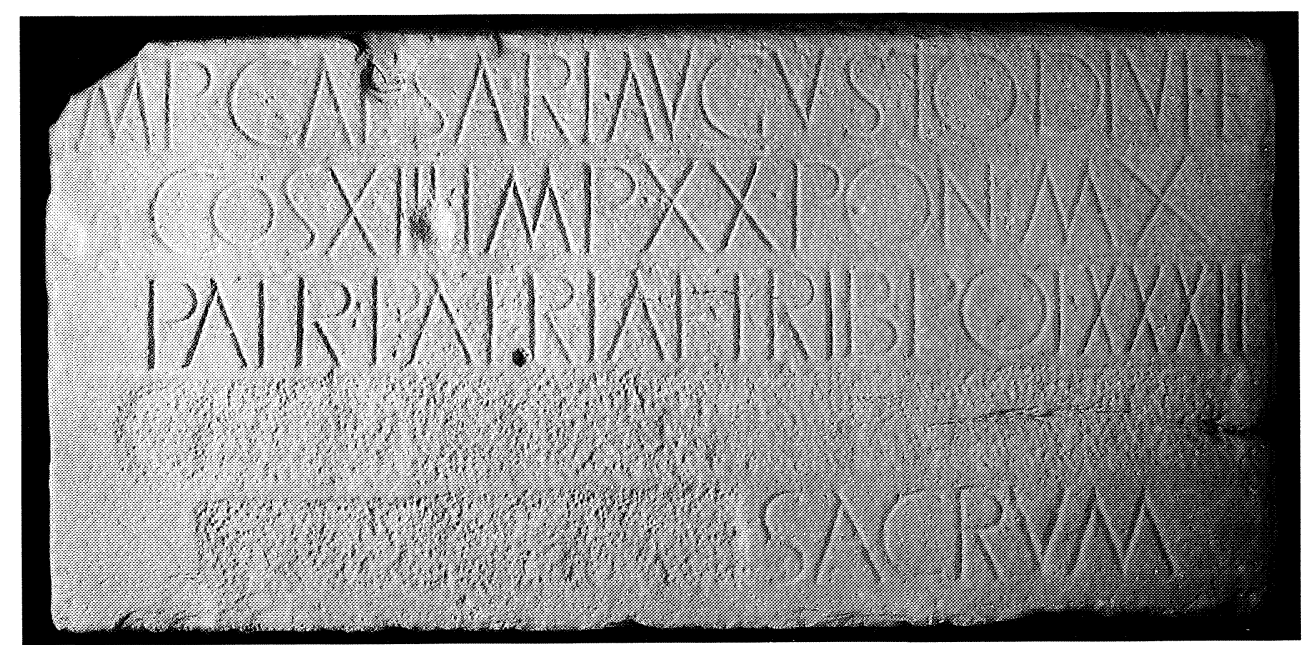

Fig. 1. Lápida de Cn. Calpurnio Pisón dedicada a Augusto hallada en Campa Torres (Fotografía: FMC Gijón).

siglos atrás, existía la polémica sobre si tan importante monumento romano se había levantado en la costa asturiana, como indicaba Mela, o en los finisterres gallegos como señalaban, entre otros, Plinio y Ptolomeo. La excavación de Reguera debía contribuir a zanjar este debate inclinando la balanza a favor de las tierras asturianas.

De la intervención de Reguera han pasado a la posteridad algunas imágenes que se han reproducido, de forma continuada y con escasas variantes, en todas las obras de historia regional o local hasta nuestros días. Se trata de un par de dibujos en planta con indicación de escala en pies castellanos que corresponderían, siempre según la historiografía regional, al lugar de la instalación de las aras en el citado castro. A partir de estas figuras, trataremos de analizar los testimonios recogidos por Reguera y transmitidos por distintos eruditos e historiadores locales a los que debemos añadir otra información de enorme interés como es la litografía realizada in situ por Nemesio Martínez Sierra en 1884, que ofrece claves de lectura de gran transcendencia para la interpretación que vamos a proponer en este estudio.

Partiendo del análisis de los restos exhumados durante los siglos XVIII y XIX, hoy en día destruidos, planteamos una hipótesis razonada sobre su interpretación como un faro romano. Analizaremos dicha cuestión en el marco general de la conquista y romanización de la costa astur, comenzando por descartar su identificación con las famosas Aras Sestianas, cuestión que ya hemos abordado detalladamente en una publicación anterior (Fernández Ochoa \& Mori1lo, 2002), para proseguir con el desarrollo de nuestra propuesta interpretativa.

\section{LA CAMPA TORRES Y LAS ARAS SESTIANAS}

La posible ubicación de las Aras Sestianas en Campa Torres se apoyó, desde antiguo, en dos argumentos principales: el primero se basaba en una cita de Mela que, al describir la costa astur, situaba las tres aras junto al oppidum Noega (Chorographia III, 13), generalmente identificado con algún establecimiento de la zona de Gijón, sea la propia ciudad o el cercano castro de la Campa Torres (fig. 2).

A favor de la localización de estos monumentos en la Campa Torres, se esgrimía una segunda razón, derivada del hallazgo de la ya citada inscripción dedicada a Augusto, que siempre se consideró procedente de este enclave. Autores de los siglos XVI y XVII como Tirso de Avilés (1556) y Marañón de Espinosa, Arcediano de Tineo (1588), localizan la lápida en el límite entre los concejos de Gijón y Carreño, siendo éste último quien indica concretamente que se encuentra en las orillas del río Aboño (Somoza, 1908: 302-303; De la Madrid, 1995: 280; Maya \& Cuesta, 2001: 24-25). Será a través de la obra del Padre Carvallo (1613), sobre unas descripciones de Ambrosio de Morales (1572), cuando se consolide plenamente la idea de identificar la lápida augustea de Campa Torres con una de las Aras Sestianas.

La Campa Torres, como es sabido, constituye uno de los castros más relevante de la costa astur, ocupado con seguridad a partir del siglo VI a. C. (Maya \& Cuesta, 2001), cuya actividad muestra un amplio arco cronológico que incluye parte de la época altoimperial y, quizá, una ocupación precaria u ocasional hasta el fin del Imperio ${ }^{2}$.

${ }^{2}$ A diferencia del periodo prerromano, conocido a través de una reciente monografía (Maya \& Cuesta, 2001), la fase 


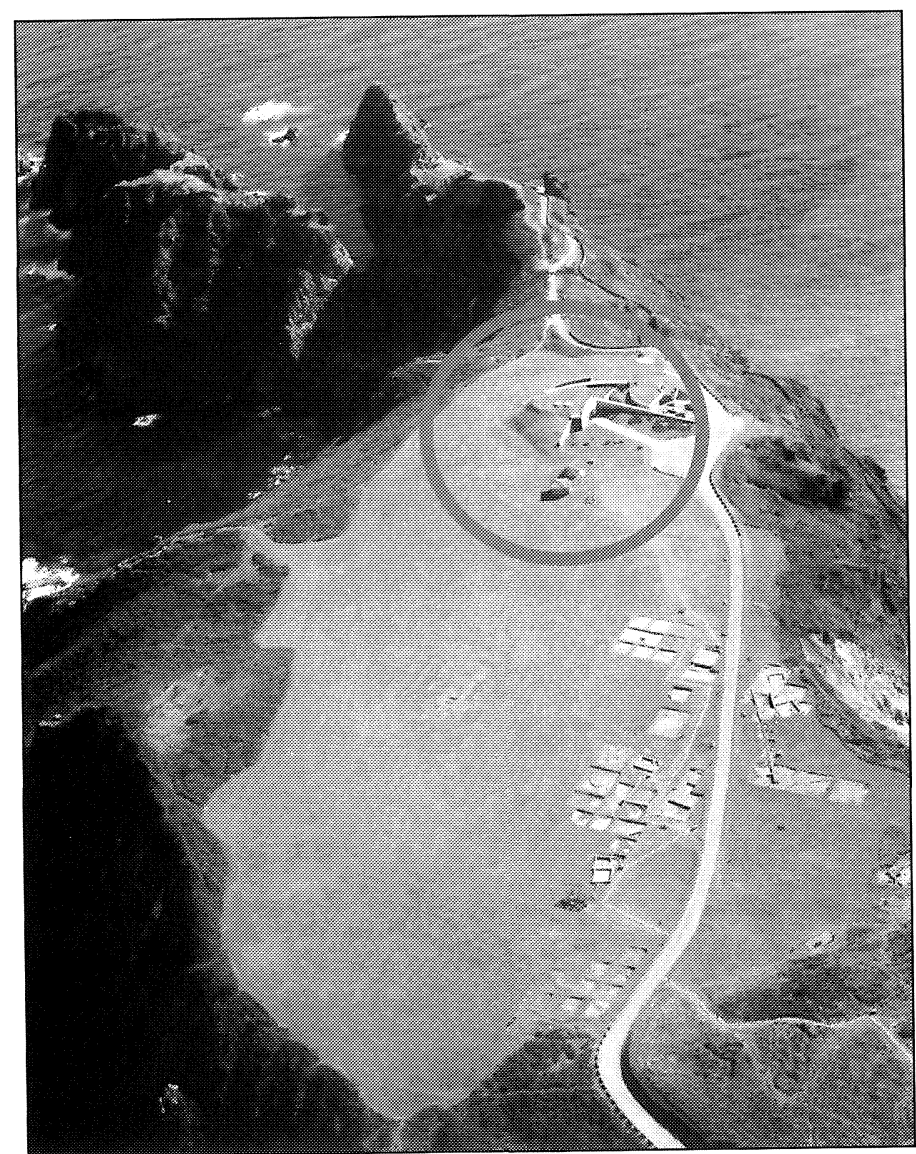

Fig. 2. Vista aérea de la península de Torres (Gijón, Asturias) (Fotografía: FMC Gijón). costa gallega. Por el contrario, Mela se aparta de esta localización y las lleva al litoral de los astures ${ }^{3}$.

Esta contradicción entre las distintas fuentes ha provocado una amplia polémica en la moderna historiografía gallega y asturiana. Hoy en día, siguiendo la opinión de Syme (1969: 129-132), existe tendencia a dar mayor credibilidad al texto de Plinio, que sitúa las aras en algún promontorio marítimo de la recortada costa gallega, situado entre Finisterre y la ría de Arosa. Sin embargo, llama la atención que Mela, bastante buen conocedor de la costa gallega hasta el Golfo Artabro, no mencione la presencia de las aras en Galicia, error que tal vez pudo deberse a una confusión al existir dos núcleos con el nombre Noega. En efecto, existió una Noega o Noeta en la costa galaica, atribuida a los copori, como deja patente Plinio ${ }^{4}$, y una localidad homónima en la costa astur, también reseñada por Estrabón ${ }^{5}$ y Plinio ${ }^{6}$. Tal vez incluso debamos sumar a las citas de estos dos autores la de Ptolomeo ${ }^{7}$, siempre y cuando consideremos que la Noega Ucesia de este geógrafo no es sino la Noega astur que por error él traslada hacia el este, justo al límite con el territorio cántabro (Fernández Ochoa, 1994: 53-60). Cabe la posibilidad de que Mela
No es nuestra intención ahora exponer en profundidad, al compás de este ensayo interpretativo, la cuestión de las Aras Sestianas, suficientemente tratada, como ya hemos dicho, en un amplio estudio al que remitimos (Fernández Ochoa \& Morillo, 2002). Quizá conviene, no obstante, recordar de forma muy breve, los términos de la polémica historiográfica y la propuesta de solución que consideramos más acorde con la información disponible.

La existencia de unas aras o altares dedicados a Augusto por L. Sestius Quirinalis, gobernador de la Citerior entre el 22 y el 19 a. C., ubicadas en una península del litoral noroeste hispano, está atestiguada en las descripciones geográficas de Mela, Plinio y Ptolomeo, además del Ravennate. No obstante, existen significativas discrepancias entre estas fuentes sobre su localización. Plinio y Ptolomeo, además del Anónimo de Ravena, las sitúan en la

de ocupación romana carece de una memoria científica y permanece inédita, por lo que no se dispone de una información contrastada al respecto.
${ }^{3}$ La Chorographia de Mela dice textualmente: «...in astyrum litore Noega est oppidum est tres arae quas Sestianas vocant in paeninsula sedent et sunt Augusti nomine sacrae ilustrantque terras ante ignobilis» (Chor. III, 13). Plinio alude a las aras en su enumeración de los pueblos galaicos: «... Celtici cognnomina Neri et Supertamarici quorum in paeninsula tres arae Sestianae Augusto dicatae, Copori, oppidum Noeta...» (Naturalis Historia IV, 111). El texto de Ptolomeo (Geographica II, 6, 3) coincide en casi todos sus términos con la Naturalis Historia pliniana: «Después del promontorio Nerio, otro promontorio en el que se hallan unas aras de Sestio». Entre las menciones a las citadas aras, debemos incluir asimismo el Anónimo de Ravena $(308,1)$, que alude a un centro viario denominado are Augusti, situado en las costas gallegas, concretamente entre Turaqua y Quecelenis. Dichos emplazamientos se suelen identificar respectivamente con Turoqua y Aquis Celenis (Caldas de Reyes) del Intinerario de Antonino, mansiones situadas sobre la vía XIX en las cercanías de la ría de Arousa. A. de la Peña Santos (1990-91: 226, nota 8) señala la afinidad fonética entre «Arauza/Arosa» y el término «ara» a favor de la ubicación de are Augusti en la región.

${ }^{4} \mathrm{NH}$ IV, 112.

${ }^{5}$ Geog. III, 4, 17-20.

${ }^{6} \mathrm{NH}$ IV, 111.

${ }^{7}$ Geog. II, 6, 6. 
asociase las Aras Sestianas con la Noega astur, posiblemente la más conocida, sin reparar en que donde se encontraban realmente las aras era junto a la Noega galaica (Fernández Ochoa \& Morillo, 2002: 901-902). Esta confusión de Mela estaría avalada asimismo por otro pasaje de su propio relato, en el que menciona una turris Augusti situada aproximadamente en el lugar donde Plinio coloca las Aras Sestianas ${ }^{8}$.

La historiografía tradicional, basándose en el problemático texto de Mela, ha intentado identificar el epígrafe del Cabo de Torres con una de las Aras Sestianas (v. infra). Sin embargo, como ya apuntó en su día A. Schulten (1943: 192-193), ninguna prueba permite asociar esta lápida con las aras erigidas por L. Sestio, e incluso la cronología atribuida a dicho documento epigráfico (9-10 d. C.) corresponde a un momento más tardío, separado casi treinta años en el tiempo del gobierno de L. Sestio, que desempeñó su cargo entre el 22 y el 19 a. C. Esta divergencia temporal tan notoria apenas ha sido tomada en consideración a la hora de ubicar las Aras Sestianas en la Noega astur (Fernández Ochoa \& Morillo, 2002: 903) ${ }^{9}$. No cabe duda que nos encontramos con una importante inscripción conmemorativa de carácter religioso, que no es una de las aras sestianas. Por lo tanto es necesario replantear por completo su interpretación, así como la de las estructuras constructivas asociadas al lugar de procedencia de este documento epigráfico.

\section{APUNTES HISTORIOGRÁFICOS SOBRE LAS PRIMITIVAS RUINAS DE CAMPA TORRES}

\section{Las primeras referencias historiográficas}

El origen de la tradición histórica que sitúa varios edificios identificados con las Aras Sestianas en el cabo de Torres se remonta a la Baja Edad Media. El Padre Carballo recoge un testimonio contemporáneo del abad de San Vicente, Don Diego, según el

\footnotetext{
${ }^{8}$ Chor. III, 11.

9 Tal y como señalábamos en este mismo trabajo, en artículos recientes se mantiene la idea tradicional que identifica la lápida calpurniana de Campa Torres como una de las Aras Sestianas, atribuyéndoles, una cronología similar «en líneas generales» a pesar de los casi 30 años que median entre ambas (Maya, 1998: 957). En este artículo, partiendo de esta argumentación y también en la línea tradicional inspirada por el texto de Mela, se propone la existencia de dos conjuntos de aras, unas en el litoral galaico y otras en el astur, siendo estas últimas las erigidas en la Campa Torres. Pero esta hipótesis deja sin resolver de forma satisfactoria el porqué supuestamente Mela denomina arae Sestianae a un monumento erigido por L. Calpurnio Pisón en la costa astur varias décadas después de terminado el gobierno de L. Sestio.
}

cual el rey Juan I visitó el lugar de las «aras», donde todavía se encontraba en pie una de ellas (Carba1lo, 1695). Mayor interés reviste la descripción de Ambrosio de Morales en 1572, quien no visitó personalmente las ruinas pero recoge un completo testimonio de las mismas en su visita a Gijón:

«Estas aras fueron tres grandes pyrámides labradas en cantería, al modo de las muy ponderadas en Egypto, y assí huecas por de dentro con sus caracoles, que subían a lo alto... Y de las dos no ay hombres en el lugar que se acuerden, porque o las ha consumido la mar, o las deshicieron para la fortificación. Mas la tercera no ha diez años que se derribó; y assí muchos me referían a mi, estando en aquel puerto (Gijón), su forma y altura, y como tenía grande inscripción con muchas letras, la qual también, como todo lo demás se consumió en edificios, sin que nadie tuviese cuenta con lo que se destruya.» (De Morales, 1586: libro 8, capítulo LVII, folio 202-203).

El topónimo «Tores» se refleja por primera vez en el Atlas de Juan de Rikzo Oliva de 1580 y, poco más tarde, es representado también en el atlas naútico publicado en Amberes en 1583 por Lucas Jansz Waghenaer (Adaro Ruiz, 1976: 34; Suárez García, 2003: passim). Algunas décadas después, en el Atlas del Rey Planeta, editado en 1634, se representan en la península de Torres unas ruinas en la zona que separa la llanada del extremo del cabo del resto, que parecen identificarse en este caso como los restos de la muralla prerromana (fig. 3).

Estas referencias constituyen el testimonio inequívoco de la fijación, cuando menos, a mediados del siglo XVI del topónimo «Torres» para denominar tanto la prominencia del cabo como la llanada que se extiende entre éste y el territorio continental. Es comúnmente aceptado que dicho término deriva de la presencia de antiguos muros en la Campa, pero tal vez provenga directamente de la existencia de algún edificio con apariencia turriforme y perfil destacado sobre el paisaje del cabo, todavía visible a mediados del siglo XVI, época en la que Tirso de Avilés localiza en este lugar una Fuente de la Talaya.

Tirso de Avilés, canónigo de Oviedo, informa hacia 1580 del paradero de la lápida consagrada a Augusto que Morales había dado por desaparecida, localizándola en una ermita entre los concejos de Carreño y Gijón, junto a la ría de Aboño y el mar. Añade en su obra una primera lectura de la inscripción, e indica que ésta procedía de un antiguo edificio derribado en la Campa Torres junto a la citada fuente de La Talaya, también conocida por «de la Pipa» (De Avilés, 1956: 211-212).

Ya en el siglo XVII, Alonso Marañón de Espinosa, Arcediano de Tineo, vuelve a situar las aras a Augusto en el límite entre los concejos de Carreño y Gijón y señala que la lápida se conserva en una 


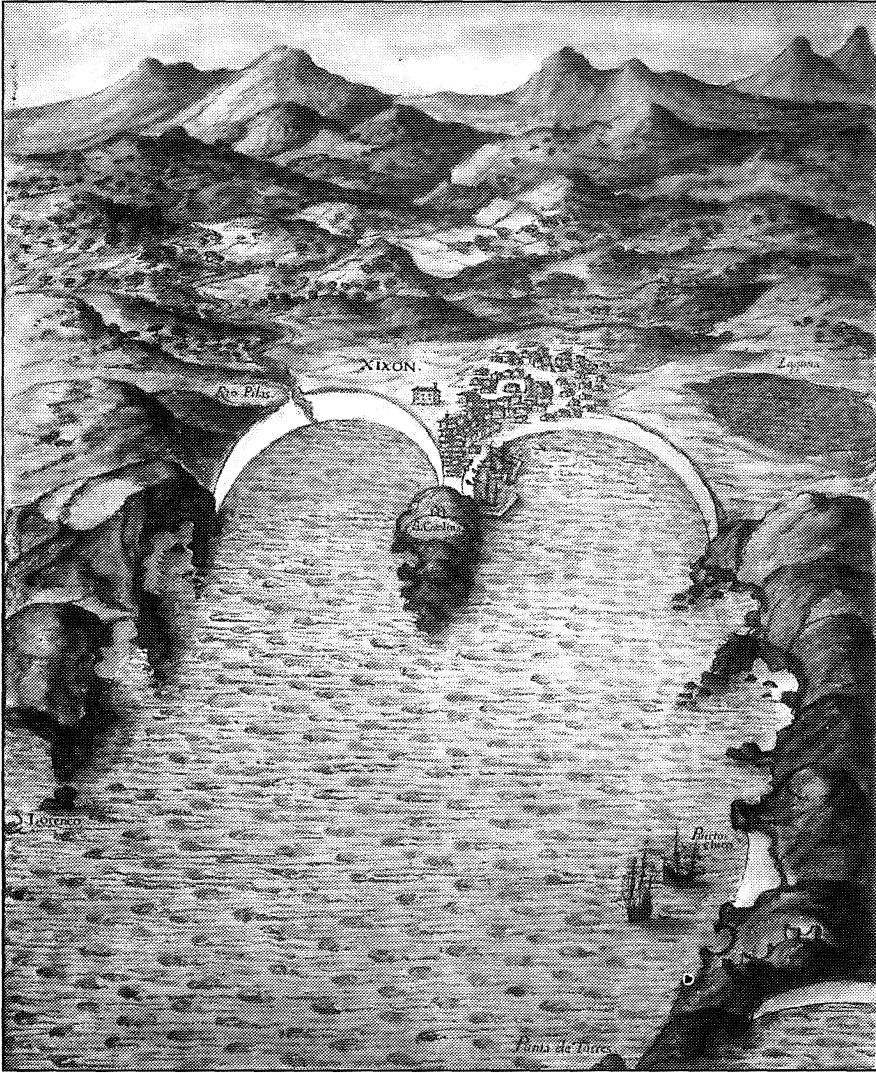

Fig. 3. Vista de la costa de Gijón según en Atlas del Rey Planeta. ramente cuestionada por autores como Jovellanos, Rendueles o Somoza, fue aceptada sin mayor crítica en obras posteriores de enorme difusión como Asturias de Bellmunt y Canella (1900) o la más reciente de Bonet Correa (1971).

Del análisis de la historiografía de época moderna, independientemente de la errónea y reiterativa identificación con las Aras Sestianas, se desprenden varios hechos incuestionables sobre las ruinas de Campa Torres. Sólo se documentan restos de un único edificio derruido en el siglo XVI (hacia 1575), si bien se mantiene el tópico de las 3 aras o estructuras constructivas diferenciadas, tomando como punto de partida el texto de Mela; las ruinas se encontraban en algún lugar de la Campa Torres cerca del mar y de una fuente; a juzgar por su asimilación formal a una pirámide, el edificio debía presentar una planta cuadrangular, de tipo turriforme $\mathrm{y}$, tal vez, escaleras; todos los testimonios conservados coinciden en que existía una única inscripción en dicho edificio, la lápida de Cn. Calpurnio Pisón conservada hoy en día, trasladada en algún momento del siglo XVI a una ermita en los alrededores. capilla a orillas del mar, que se inunda en momentos de fuertes mareas y cuya localización es aún hoy desconocida (1614: 10-11). A mediados del siglo XVIII, según Risco, la lápida se encontraba en posesión de los marqueses de Peñalba, sirviendo como mesa de altar en su capilla privada de Carrió, localidad próxima a Gijón (Risco, 1789: 40). En esos mismos años, Flórez (1759: 52) advierte del error de confundir las aras con la pirámide, aunque dicha apreciación deriva no de una observación directa de las ruinas, sino de una reinterpretación del texto de Mela (III, 1, 9).

Durante el siglo XVIII diversos autores mantienen la interpretación de Ambrosio de Morales sobre las ruinas de la Campa Torres. Así es recogida por Mariana, y ampliamente difundida con las obras de Carballo y, sobre todo, de Menéndez Valdés. Este autor añade incluso un disparatado dibujo de las tres pirámides mencionadas por Morales, que representa con base triangular en lugar de cuadrada (Menéndez Valdés, 1779-1804). Estos autores consideraron siempre que la lapida de Torres formaría parte de este curioso conjunto cuya veracidad, aunque seve-

\section{LAS «CONSTRUCCIONES» EXHUMADAS POR MANUEL REGUERA GONZÁLEZ (1783)}

La intervención de jovellanos abrió una fase completamente distinta en el conocimiento de la ruina. En los Apuntamientos sobre Gijón que redacta en 1804 para el Diccionario de Martínez Marina, recientemente descubiertos y editados (González \& López, 2001: 15), Jovellanos narra una visita realizada al Cabo Torres en 1782 con la intención de explorar los restos antiguos aún visibles y dilucidar la posible localización de las Aras Sestianas en este enclave ${ }^{10}$.

«... un curioso ( ...) pasó un día a Torres, reconoció gran parte de la superficie del cabo, vio en él restos de un antiguo edificio $y$, faltándole tiempo para concluir o repetir su examen, instando el de su partida, dejó este

${ }^{10}$ Como señala Somoza, Jovellanos manifestó siempre un gran interés por descubrir el enigma de las Aras Sestianas (Somoza, 1908: 318). Los textos de Jovellanos recogidos en el presente trabajo proceden de la cuidadosa y documentada edición preparada por Javier González Santos y Xuaco López (González \& López, 2001). 
encargo al erudito don Miguel de Jovellanos, abad de Villoria y al arquitecto académico don M. Reguera González que lo desempeñaron completamente. Hicieron la necesaria excavación para descubrir todo el cimiento, lo reconocieron, midieron y levantaron su plano que por desgracia pereció también ${ }^{11}{ }$.

El encargo de Jovellanos sobre la excavación de las ruinas de la Campa Torres fue ejecutado con fidelidad por Reguera. Éste le notifica, en una carta fechada en julio de 1783, que se están llevando a cabo los preparativos para la intervención ${ }^{12}$, que debió de producirse en fechas inmediatas. Como consecuencia de sus actuaciones, Reguera elaboró un informe y un dibujo a escala con el plano de los restos exhumados, en el que se reconocen dos estructuras. Somoza notifica que el 4 de noviembre de 1783 se elevó dicho informe con los resultados obtenidos al Ayuntamiento de Gijón (Somoza, 1908: 804). Años después, Jovellanos, que escribe sus Apuntamientos desde su destierro en el castillo de Bellver y sin disponer de suficiente documentación ${ }^{13}$, describe los restos de memoria:

«Era un edificio pequeño, perfectamente escuadrado, con dobles muros por sus cuatro lados, todos perpendiculares: los interiores paralelos y colocados a distancia suficiente de los de afuera para que pudiesen unirse por medio de una escalera en caracol. La obra era de mampuestos unidos por un mortero de argamasa sin arena, y todo, al parecer, romano. $Y$ aún me parece que uno de los ángulos indicaba tener arranque como para alguna continuación de la obra. Téngase todo presente, juntamente con la forma de las aras que describe Mariana (y no sé de donde la sacó; aunque de la misma ropa ${ }^{14}$ y tiempo que Carballo, pudo sacarla de sus informes)».

A Jovellanos, como ya se ha dicho, le interesaba especialmente dar cuenta de la inscripción dedicada a Augusto, de su contenido y ubicación concreta. Por ello, su narración en los Apuntamientos posee un extraordinario interés para nuestro estudio, pues transmite datos solventes acerca del lugar y condiciones del hallazgo de la lápida que, además, concuerdan con los recogidos por otros autores contemporáneos.

"Varios dijeron entonces haberla visto sobre la superficie del cabo y en el sitio de aquella ruina, aunque suelta y separada de la restante obra. Dijeron también que muy entrado ya el siglo XVIII la había hecho transportar el señor don Gaspar de Carrió, padre de la actual condesa de Peñalva, a la casa que tiene en el lugar de

${ }^{11}$ Como veremos más adelante, se conservaron copias de estos planos.

${ }^{12}$ La misiva se incluye en el vol. II de las Obras Completas de Jovellanos (cf. De la Madrid, 1995: nota 607).

${ }^{13}$ Cf. López Álvarez, 1997: 273.

${ }^{14}$ Los editores aclaran que esta expresión hace referencia a que Mariana y Carballo eran jesuitas (González Santos \& López Álvarez, 2001: nota 36). su apellido, situada al otro lado del río Aboño. Allí existe actualmente, formando la mesa del altar de su capilla pública y precisamente detrás del frontal».

Investigaciones recientes revelan la peripecia de la documentación sobre las primitivas ruinas de la Campa Torres a lo largo del siglo XIX y comienzos del XX poniendo de relieve que las copias del informe y los planos eran sobradamente conocidos en el ambiente erudito gijonés. De hecho, el informe con los planos (o copias del mismo) estuvieron archivados durante años en el Real Instituto Jovellanos de Gijón hasta su desaparición durante la guerra civil (De la Madrid, 1995: 281).

En efecto, volviendo sobre el citado informe, hoy en día se sabe que ya en 1784 el propio Reguera envió una copia a Gregorio Menéndez Valdés que estaba elaborando su famosa Historia de la antigua ciudad de Gixa $^{15}$ (De Blas \& González, 1989: 9193), si bien será Rendueles Llanos en 1867 quien publique, por vez primera, los planos y un resumen del informe que le había proporcionado Juan Junquera Huergo (1804-1880), personaje que jugó un importante papel como Director del Real Instituto Jovellanos y buen conocedor de su Archivo (Rendueles, 1867: 18-19).

A los efectos que ahora nos interesan, la interpretación del informe y planos de Reguera es coincidente en todos los autores posteriores puesto que se alimenta de los datos que le fueron suministrados a Rendueles por Junquera Huergo (Rendueles, 1887: 18) (Fig. 4). El informe dice así:

«En el año pasado de 1783, por D. Manuel Reguera González maestro arquitecto, académico de mérito de la real academia de San Fernando de la villa y corte de Madrid, director de las obras de los muelles y dársenas de la villa de Gijón, y su real carretera a Oviedo, vecino de esta ciudad y natural del noble concejo de Carreño, se descubrieron los cimientos y vestigios de la situación que tuvieron las aras sestianas y sitio de la mesa en que sacrificaban los romanos a sus deidades en el cabo llamado de Torres, lateral a la rada y concha de dicho puerto ó villa de Gijón, fronteando a ella por la parte del vendaval, en cuyo cabo se observan ruinas y fragmentos de otros edificios y la explicación es la siguiente: Número $1^{\circ}$.- Macizo de altar.$2^{\circ}$.Tránsito o andenes que la circuyen. $-3^{\circ}$. Macizo de paredes que cierran dichos tránsitos. $4^{\circ}$. Otro edificio inmediato a dicho altar que pudo ser el de las aras o tener otro destino etc. Todo construido con la mayor perfección y solidez y las partes interiores de ajustada y bien labrada cantería etc.

15 En la edición preparada por Luis Adaro Ruíz-Falcó (1986) de la obra de Menéndez Valdés se incluyen los datos de Reguera como «recién descubiertos» pero no se alude a la carta enviada por éste a D. Gregorio (De Blas \& González, 1989) que confirma la existencia de copias y la transmisión del resultado de los hallazgos a las personas interesadas en el asunto, como era el caso de Menéndez Valdés. 


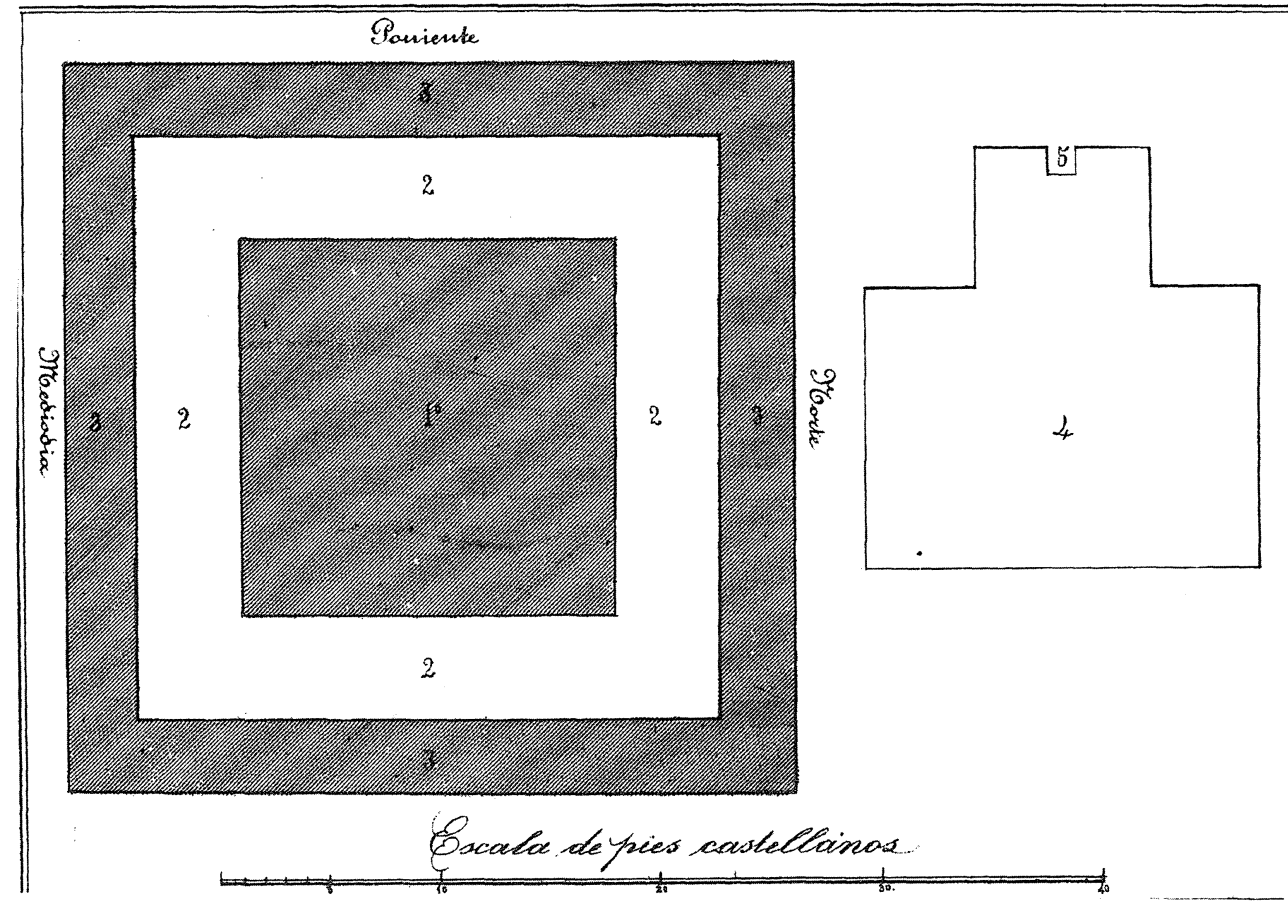

Fig. 4. Plano de las excavaciones realizadas por el arquitecto M. Reguera en 1783, reproducidos en el libro de E. Rendueles en 1867.

La anterior carta, noticia y planta están copiadas del mismo original, escritas todas y estendidas y firmadas de puño y letra por el mismo Reguera González.- Juan Junquera Huergo».

Para finalizar este apartado, podemos recordar brevemente algunos comentarios y observaciones de Somoza al abordar el problema de Gijón y las Aras Sestianas (Somoza, 1908: 299-322). Su constante posición crítica sobre las «historias» de Gijón así como su conocimiento del terreno, constituyen una fuente informativa de primera mano. Somoza se reafirma en la tradición de la presencia de las Aras Sestianas en Gijón. Basándose en el texto de Mela, acepta su procedencia del Cabo Torres e incluso, al describir el excepcional lugar que ocuparían estos monumentos, propone que podían haber pertenecido a un faro:

"...a $150 \mathrm{~m}$. de elevación sobre el nivel del mar, dominando la línea del horizonte marítimo, y a la entrada del puerto de Gijón, dan visos de probabilidad a la especie de que pudieran servir de ornamentación de un faro. Antes, citamos el de La Coruña (faro de Hérkules); ahora diremos que al pié del mismo, se encuentra una inscripción romana dedicada a Marte, con el nombre del arquitecto lusitano que lo construyó».

Sobre los restos excavados por Reguera en el lugar donde se ubicarían las Aras Sestianas, Somoza (1908: 318), dirá:
«En ellas (las excavaciones) se descubrieron los cimientos de dos edificios, uno que debía ser el que contuviera las Aras; y otro, contiguo a él, de ignorado destino (que a algunos se les antojó un altar de sacrificios). El primero, de forma casi cuadrada, tenía 9 m. 196 de lado, lo que da una superficie de 89 m.c. , 56. El segundo en forma de $T$, era de más reducidas dimensiones. Aún quedaron muchos parages por descombrar que presentaban vestigios de ruinas, montículos, fosos, y fragmentos de edificios».

Por otra parte, manifestará su decepción ante los restos conservados cuya descripción historiográfica tradicional tacha de exagerada:

"Visitamos esta ruina (también por vez primera) en 1871 y confesamos que se nos enfrió mucho el entusiasmo al ver a cuan exiguas proporciones quedaba reducido aquello de un edificio digno de la magnificencia romana y lo otro de un venerable monumento de la antigüedad».

Desde mediados del siglo XIX, existe un cierto interés en la Comisión Provincial de Monumentos por las ruinas de Torres que, en ocasiones, llega a alcanzar visos de preocupación por la suerte y la importancia de una restos que merecerían una nueva excavación (Adan, 1997: 215) que, al parecer, se llevó a cabo en 1884, no sin levantar polémica entre sus miembros. 


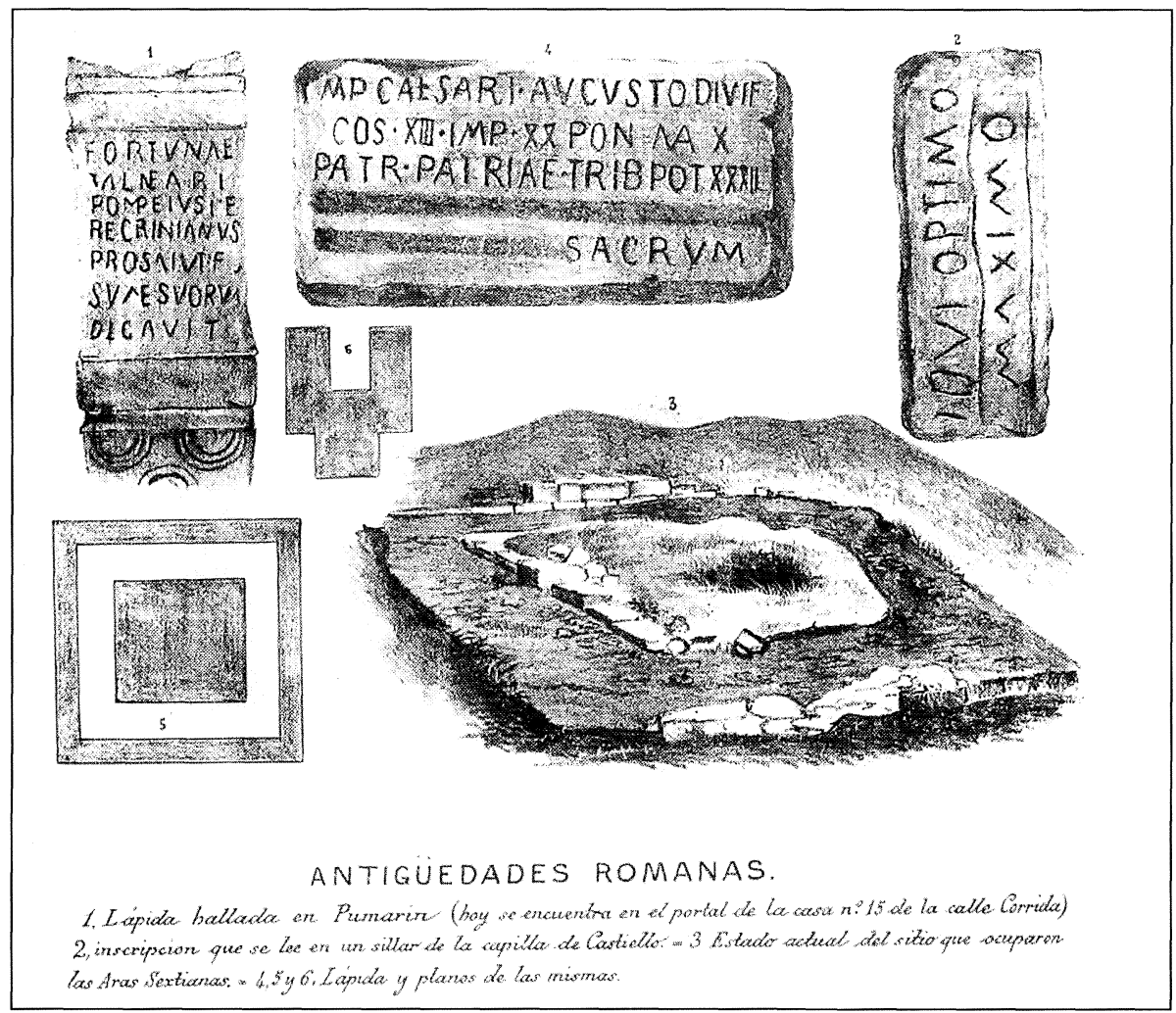

Fig. 5. Litografía de N. Martínez, donde se recoge la situación de las ruinas tras las excavaciones de 1884.

\section{LA LITOGRAFÍA DE NEMESIO MARTÍNEZ SIENRA (1884)}

El segundo documento importante para aproximarnos a la reinterpretación gráfica de las primitivas ruinas del Cabo Torres lo constituye la litografía de Nemesio Martínez Sierra, incluida en su Guía Ilustrada de la Villa y Puerto de Gijón editada en 1884 y subtitulada, «Idea general de su movimiento fabril y colección de vistas sacadas del natural». En la lámina «Antigüedades Romanas» (Martínez Sienra, 1884, reed. de 1986: 71) este conocido dibujante gijonés reproduce las lapidas de la Fortuna $\left(\mathrm{n}^{\circ} 1\right)$ y de Júpiter ( $\left.\mathrm{n}^{\circ} 2\right)$, y unos dibujos de las ruinas de Campa Torres con la siguiente indicación: 3. Estado actual del sitio que ocuparon las Aras Sextianas.- 4, 5 y 6. Lápida y planos de las mismas (fig. 5).

La historiografía de finales del siglo XIX y de todo el siglo XX ha reproducido esta lámina en todas las consideraciones sobre las Aras Sestianas, sin reparar en que la litografía incorpora información inédita en el plano tradicional de Reguera. Nos referimos a la vista general de las ruinas, donde se representan, sobre un horizonte paisajístico recono- cible, detalles arquitectónicos del mayor interés, entre otros, la fábrica de sillería que mostraban las hiladas inferiores del monumento. De particular utilidad en su interpretación resulta el pie por el que se hace constar «estado actual del sitio», al contextualizar la imagen, editada en 1884, en la misma época en que se realizaron las excavaciones referidas en la Campa Torres por la Comisión Provincial de Monumentos. Pensamos, por ello, que nos encontramos ante un dibujo realizado al término de aquella intervención de la que, por otra parte, se carecía de cualquier testimonio gráfico. Resulta sorprendente que los autores contemporáneos no hayan constatado que la aportación de Martínez no se limita a una simple visión romántica de un edificio arruinado, sino que ofrece el resultado de una intervención arqueológica. Su valor de cara al conocimiento de la ubicación exacta de las ruinas, así como a la forma y las características constructivas de las mismas, resulta mucho mayor.

Aquel mismo año de 1884 la prensa gijonesa denuncia el expolio de los restos que las excavaciones acababan de sacar a la luz (Maya \& Cuesta, 2001: 27 , nota 16 ). 


\section{LA INVESTIGACIÓN ARQUEOLÓGICA EN EL SIGLO XX}

A pesar de aquellos hechos, todavía en 1895 Rato y Roces tienen oportunidad de reconocer los vestigios y realizar la primera fotografía que se conoce de los mismos (1895: 137). Los trabajos aparecidos con posterioridad se limitan a reproducir los datos y las imágenes ya conocidas. La guerra civil supone una pérdida irremediable tanto para el monumento, desaparecido probablemente debido a la construcción de búnkeres en el extremo del cabo de Torres, como para la documentación existente sobre el mismo que se perdió junto con otros importantes archivos gijoneses. Tan sólo se conserva la inscripción, trasalada 1894 a la casa de Atanasio Ávila, en Luanco, y finalmente adquirida por Joaquín Manzanares en 1960, en manos de cuyos herederos se mantiene en la actualidad. Francisco Diego Santos realiza en los años cincuenta el primer estudio científico de la pieza (ERA: 61).

La investigación desde mediados del siglo XX se limita a reproducir sistemáticamente la descripción de la lápida, las ilustraciones de Reguera y de Martínez y la consabida identificación de la pieza con las Aras Sestianas, siendo J. M. González el primero en proponer la identificación del yacimiento de la Campa de Torres con el oppidum Noega de las fuentes (1978: 24).

Las aportaciones principales de las últimas décadas se han centrado principalmente en el campo de la historiografía (De Blas \& González, 1989; De la Madrid, 1995), mientras desde un punto de vista arqueológico, el comienzo en 1982 de las intervenciones sistemáticas en el yacimiento, como parte del Proyecto Gijón de Excavaciones Arqueológicas, no ha incidido en el conocimiento del edificio romano asociado a la inscripción (Maya \& Cuesta, 2001; Fernández Ochoa, 2003). Recientemente, publicamos un artículo sobre esta cuestión, donde proponíamos la necesidad de romper la asociación automática que la tradición había establecido, sin fundamento científico, entre la lápida y el monumento que la albergó, por una parte, y las Aras Sestianas, por otra (Fernández Ochoa \& Morillo, 2002).

\section{EL MONUMENTO ROMANO DE CAMPA TORRES Y LA INSCRIPCIÓN DE AUGUSTO: NUEVAS PROPUESTAS INTERPRETATIVAS ${ }^{16}$}

A pesar de las limitaciones expuestas en el conocimiento de las viejas construcciones elevadas sobre

16 Agradecemos a nuestra compañera, la Dra. Rosalía Durán Cabello, su buena disposición a la hora de reflexio- el cabo de Torres, la documentación disponible sí permite una aproximación no despreciable a las características formales y también de orden estructural que pudieron poseer aquellos edificios. Su interpretación parte, en consecuencia, de una realidad que, aunque teñida del subjetivismo consustancial a este tipo de lectura artística, ofrece elementos suficientemente explícitos y verosímiles para su consideración. Estos testimonios, aceptados así como documento arqueológico, constituyen los argumentos de partida de una propuesta de interpretación que pretende, comprender y justificar la naturaleza de unas ruinas carentes, hasta la actualidad, de cualquier significación en el discurso histórico elaborado en torno a un asentamiento de relevancia tan notable como es el de la Campa Torres.

Los planos elaborados por Reguera en el siglo XVIII, que confirman las descripciones anteriores, $\mathrm{y}$ la litografía de Nemesio Martínez ofrecen una referencia suficiente para considerar probada la existencia de dos edificios, en principio diferenciados, que transmiten cierta intención de monumentalidad.

El edificio de mayor envergadura es una construcción de planta cuadrangular delimitada por un muro perimetral de $1,05 \mathrm{~m}$ de anchura y una longitud de $9,24 \mathrm{~m}$, que inscribe en su interior una segunda construcción también de planta cuadrada de 4,76 m de lado con muros paralelos a la anterior. Entre ambas discurre un ambulacrum de 1,40 m. de anchura ${ }^{17}$, que probablemente albergó una escalera interior. Mientras el muro perimetral parece estar realizado en sillería, con dos paramentos, uno exterior y otro interior, la fábrica de la construcción interior se describe como maciza, pudiendo tratarse, por tanto, de un núcleo de opus caementicium con revestimiento de sillares ${ }^{18}$. La correspondencia formal que manifiestan los dibujos realizados por Reguera y Martínez, a pesar del siglo transcurrido entre ambos trabajos, implican una indiscutible garantía respecto la credibilidad de lo representado. Por otro lado, su probable fidelidad al motivo original se ve avalada por la familiaridad que el tipo de construcción representada guarda con determinadas manifestaciones arquitectónicas de la Antigüedad, que hoy se saben partícipes de cierta estandarización.

nar sobre la interpretación arquitectónica que aquí presentamos.

${ }^{17}$ Las medidas se han tomado a partir del plano de Reguera en pies castellanos con la consiguiente conversión: 1 pie castellano $=28 \mathrm{~cm}$. La correspondencia variable atribuida según qué autores a estas unidades de medida podría hacer variar ligeramente las dimensiones propuestas, sin que ello implique, en todo caso, alteración en las proporciones.

${ }^{18}$ Por lo que respecta a la técnica edilicia, las descripciones historiográficas se ven refrendadas por la imagen de Nemesio Martínez. 
Lamentablemente no ocurre lo mismo con el segundo de los edificios representados. Los rasgos que caracterizaron esta segunda estructura tan sólo pueden ser inducidos a partir de los dibujos de su planta pues carecemos de cualquier otro elemento, gráfico o textual, que ajuste de forma más precisa su descripción. Este tratamiento diferencial sugiere que ya en su momento fue considerado de menor entidad. Una dificultad añadida es la ausencia de referencias espaciales que permitan determinar su posición, al menos, respecto al edificio principal, pues ambas láminas ofrecen localizaciones no coincidentes. Esto, siempre y cuando se considere que los elementos representados corresponden al mismo edículo, pues son tales las discordancias que expresan los planos de Reguera y Martínez que no aconsejan descartar la posibilidad de que se trate de unidades constructivas distintas.

La obra de Reguera refleja un cuerpo principal, macizo, y de planta cuadrangular de unos $5 \mathrm{~m} \mathrm{de}$ lado, que por retranqueo de las esquinas de uno de ellos determina un cuerpo menor avanzado en posición central de unos $2,80 \times 1,56 \mathrm{~m}$ que presenta en su frente una muesca rectangular de difícil interpretación. La litografía de Martínez, realizada tras la reexcavación de 1884 muestra el edículo, identificado con el número 6, sin escala ni referencia espacial alguna respecto al primer edificio. Su fisonomía, aunque semejante, muestra modificaciones de cierta relevancia. Se mantiene el machón avanzado sobre el cuerpo principal pero éste, no se muestra como el cuerpo macizo descrito por Reguera, sino que describe, por retranqueo del lado opuesto, un hueco rectangular abierto al exterior que le proporciona forma de «u». Alteraciones de tal entidad podrían justificarse por la degradación y expolio del revestimiento de sillares que, al igual que en el edificio anterior, podrían haber enmascarado el núcleo de hormigón, relicto principal de las estructuras descritas por Reguera y Martínez.

El silencio documental en torno a esta ruina es absoluto hasta las excavaciones impulsadas por Jovellanos en 1783 , hecho que parece indicar su descubrimiento en el curso de aquella aventura arqueológica, bien como estructura exenta, bien como obra asociada, sino integrada, en el hemos venido denominando edificio principal. Debe recordarse en este punto que Jovellanos en su descripción -donde tan sólo refiere la existencia de un edificio- advierte expresamente la continuidad de la obra planteando así una evidente contradicción -tal vez, correcciónal dibujo de Reguera que ignora, en principio, toda alusión a este hecho.

Las investigaciones arqueológicas más recientes no han aportado mayor información, habiéndose supuesto el enterramiento o definitiva destrucción de los restos como consecuencia de las obras de fortificación del cabo durante la guerra civil (Maya \& Cuesta, 2001: 27).

Hasta aquí la documentación conocida acerca del conjunto arquitectónico que la tradición señala como localización original del celebérrimo epígrafe a Augusto. De la descripción aportada por aquellos que, de una forma $u$ otra, tuvieron conocimiento directo de las ruinas puede concluirse el origen netamente romano de la obra y el carácter monumental que sus dimensiones y estructura denuncian. La ausencia, por otro lado, de cualquier indicio que pudiese señalar un uso doméstico o industrial subraya la vocación de edificio singular y sobresaliente que animó su construcción y que le proporcionó entidad suficiente para destacar, aún después de su ruina, entre el resto de estructuras dispersas sobre la península de Torres.

El lugar escogido para su emplazamiento posee todos los atributos requeridos para sumar significación a una obra que, por sus características, denuncia su evidente intencionalidad ideológica, ya sea política o religiosa, si es que ambas admiten disociación en el ámbito histórico tratado. La Campa Torres es un accidente geográfico de cierta relevancia en la costa cantábrica, se encuentra flanqueado hacia poniente por la desembocadura en amplia y resguardada ría del Aboño y, hacia el este, su proyección marítima origina el refugio más seguro y de mayor calado de cuantos se conocieron en la costa astur. Tras el foso y las murallas que defendía el acceso desde el continente, se estableció el castro más extenso conocido en el área trasmontana y al que cabe suponer un papel destacado entre las comunidades indígenas prerromanas. En estas condiciones, la erección de cualquier monumento adquiere una dimensión que amplifica extraordinariamente la efectividad de su mensaje y la autoridad del emisor, en este caso el Estado Romano.

Los planos de Reguera muestran un macizo, probablemente de hormigón, de superficie algo superior a los $20 \mathrm{~m}^{2}$ circunscrito por un muro de sillares que alcanza 1,05 $\mathrm{m}$ de potencia. Una base de semejante solidez sólo se justifica en previsión de un importante desarrollo vertical de la construcción, es decir, la erección de una torre.

Un cálculo prudente a partir de estos datos permite proponer como hecho factible el desarrollo de dos cuerpos superpuestos de sección probablemente decreciente que, hasta cierto punto, justificarían la primitiva y disparatada lectura de las ruinas como estructuras piramidales, impresión que, sin duda, acentuaba la acumulación de escombros en su base. 
Sin descartar la posibilidad de un tercer cuerpo que culminase la estructura, ésta pudo alcanzar sin mayor riesgo, los 15-20 m de altura. La circulación interior se realizaría mediante escaleras de tramo recto y cuarto de vuelta en $90^{\circ}$ que ocuparían el espacio descrito en planta como pasillo o ambulacrum.

El edificio descrito, con las restricciones y cautelas derivadas de documentación disponible, corresponde a un modelo muy característico de turris romana, con claros antecedentes en modelos helenísticos. La aplicación de este tipo arquitectónico es muy conocida en monumentos funerarios de época romana (Gros, 2001: passim), pero no cabe duda de que debieron existir muchas construcciones de esta misma traza con diferentes finalidades, entre las que conocemos su uso como recintos defensivos de carácter militar, trofeos y monumentos conmemorativos, sin olvidar, por supuesto, los faros.

Por lo que se refiere al segundo edificio, resulta extremadamente difícil atribuirle una función. Su planta y estrecha relación con el anterior podrían apuntar, tal vez, hacia un recinto con un altar de sacrificios que encuentra referentes en el modelo del ara pacis, pero tampoco podríamos descartar que simplemente constituyera la plataforma de acceso a la turris. De hecho, las estructuras identificadas en los dibujos se corresponden, en palabras de quienes conocieron la excavación, con los fundamentos del edificio, circunstancia que permite considerar su posible comunicación en cotas superiores.

Las descripciones más antiguas sitúan en esta torre la inscripción monumental dedicada a Augusto por Cn. Calpurnio Pisón (De Morales, 1586; De Avilés, 1956: 211-212). Dicho epígrafe, también de unas dimensiones considerables $-1,62 \mathrm{~m}$ de longitud y $80 \mathrm{~cm}$ de altura-, está labrado para formar parte de un paramento, $y$, con toda seguridad, para ser colocado en un lugar preeminente. Teniendo en cuenta además que la lápida hace referencia a una consagración, no parece improbable que se esté sacralizando el lugar al que está destinada la inscripción, esto es, el monumento en su conjunto. Existen ejemplos de monumentos consagrados de forma genérica a Augusto (Arco de Bará, trofeo de La Turbie) o a una divinidad concreta como Marte (trofeo de Adamclissi, Torre de Hércules). Allí donde ha sido posible verificarlo, la inscripción dedicatoria se encuentra bien visible y en la fachada principal. Parece lógico pensar que la inscripción de la Campa Torres ocupara un lugar semejante en el monumento desaparecido ${ }^{19}$.

${ }^{19}$ Las referencias escritas más antiguas parecen coincidir en que la lápida se encontraba colocada en el único edificio
Por otra parte, el gran tamaño de la pieza hace improbable que el conjunto de los sillares empleados en la obra fuera de las mismas dimensiones. Más bien parece que se grabó sobre un sillar de mármol que también destacara respecto a los de su entorno tanto en el tamaño como en el material empleado. El gran sillar grabado con la inscripción dedicatoria debió de ser importado, ya que no se conoce material de este tipo en Asturias ${ }^{20}$, ni officinae epigráficas activas en un momento tan temprano. Ningún otro resto de material constructivo ha llegado hasta nosotros. El desmantelamiento definitivo de la torre durante la segunda mitad del siglo XVI debió llevar aparejado una reutilización de los sillares en otros edificios, quizás en la construcción del malecón de puerto gijonés, tal y como aparece representado en 1635 en el conocido grabado de D. Fernando Valdés. Pero, como hipótesis, nos inclinamos por la utilización de cantería local de arenisca, de menor tamaño y muy fácil de conseguir en la zona, para la construcción del edificio romano.

A pesar de que la interpretación del monumento sigue planteando numerosas cuestiones, contamos con una estructura arquitectónica claramente turriforme ubicada en una eminencia al borde del Cantábrico, que ha proporcionado una inscripción monumental, la primera y hasta ahora única conocida de estas características en el norte peninsular, que alude a una consagración genérica a Augusto en el 910 d. C. La conjunción de todos estos elementos, en un momento tardoaugusteo y en una región recién pacificada e intensamente militarizada, nos remite a un escenario en el que la iniciativa oficial y su correspondiente intencionalidad política debe tenerse muy presente. Como ya hemos señalado en otra ocasión, la lápida calpurniana de la Campa Torres debió formar parte de un gran monumento edificado al final del reinado de Augusto en la costa astur, que sólo pudo ser fruto de una acción oficial muy bien definida, en la que el ejecutor material bien pudiera haber sido el ejército, sobre el que todavía debía descansar en estas fechas buena parte de la organización de los nuevos territorios ${ }^{21}$. Tal vez $\mathrm{Cn}$. Cal-

entonces visible, esto es, la estructura turriforme (v. supra). Ningún dato permite relacionar la inscripción con el segundo edificio, aunque una consagración de estas características hubiera encajado también en un posible altar (v. Alföldy et alii, 2003: 258-260).

${ }^{20}$ Teniendo en cuenta las circunstancias que rodean el depósito actual de la pieza, en una colección privada de difícil acceso no ha sido posible efectuar un análisis del soporte material de la inscripción que confirmara su procedencia hispana o foránea.

${ }^{21}$ Trabajos recientes han propuesto a partir de estudios sobre el numerario y secuencias estratigráficas bien acotadas cronológicamente, la utilización de poblados fortificados pre- 


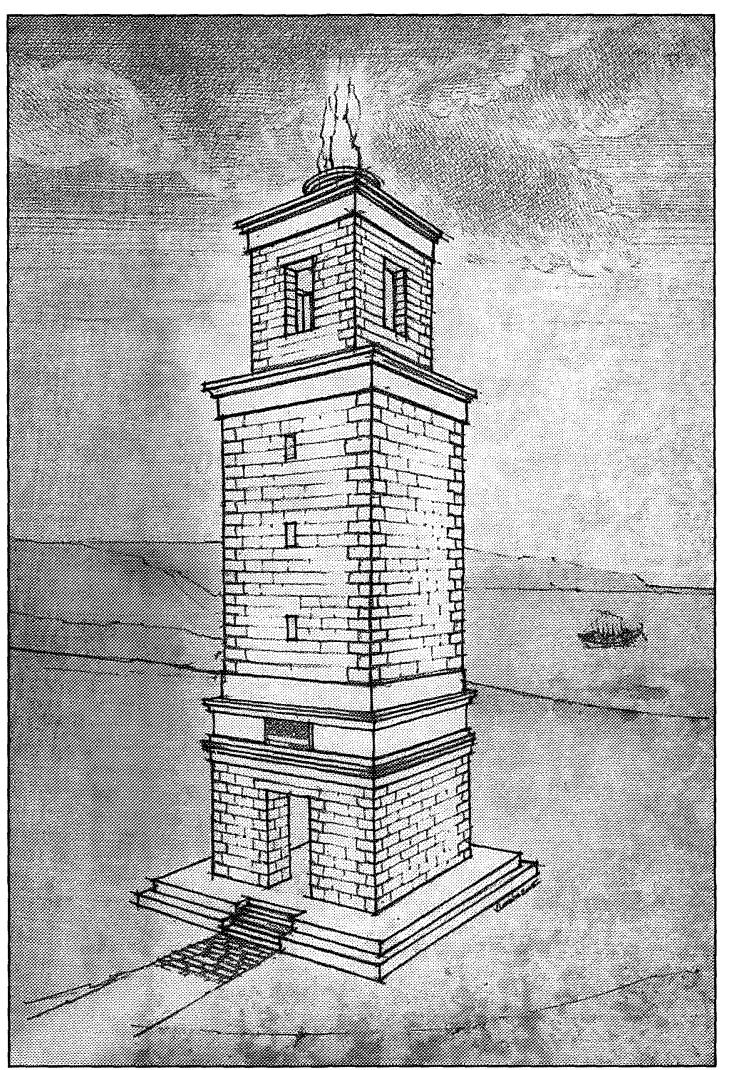

Fig. 6. Recreación de la torre de Augusto en la Campa Torres (Dibujo: Martín Vega Lorente).

purnio Pisón quiso realizar durante su gobierno un monumento conmemorativo de algún suceso acontecido años antes, posiblemente durante la conquista, como la llegada de las tropas romanas al extremo del mar Exterior, con el mismo valor simbólico que revistieron unas décadas antes las Aras Sestianas en los finisterres galaicos.

La erección de monumentos sacros de carácter simbólico es una costumbre perfectamente atestiguada en época augustea, como demuestran el trofeo de La Turbie (Lamboglia, 1983), erigido en conmemoración de la victoria augustea sobre los pueblos alpinos ${ }^{22}$, el trofeo triple de Lugdunum Convenarum, erigido en memoria de las victorias de Augusto en Actium, la Galia e Hispania (Picard, 1947: 552; Boube, 1996), o el altar construido al princeps en Tarraco $^{23}$, sin olvidar la presencia de la propia ara pacis en la capital del Imperio. Estas aras, tro-

existentes como lugares preferente en el estacionamiento de las tropas destacadas en los territorios astures trasmontanos (Gil Sendino \& Villa, 2005: e. p.; Villa et alii, 2004: e. p.).

${ }^{22}$ Plinio, NH III, 20.

${ }^{23}$ Quintilano, Institutiones III, 6, 67. feos o torres de carácter simbólico o conmemorativo tienen una intencionalidad más política que religiosa, a pesar de su sacralización ritual (Fernández Ochoa \& Morillo, 2000: 904-905).

Teniendo en cuenta la posición del cabo de Torres en la zona central de Asturia trasmontana, donde finaliza la principal arteria de comunicación con la Meseta, y en el lugar donde se ubica uno de los escasos fondeaderos naturales (Fernández Ochoa et alii, 2003) y el mayor asentamiento de los astures, el oppidum Noega, la edificación de un gran monumento con forma de torre dedicado a Augusto estaría profundamente cargada de significado simbólico para quienes accedieran por tierra o por mar a la ya sometida región transmontana (Fernández Ochoa \& Morillo, 2002: 904). No debemos olvidar que el acantonamiento de la legio VI victrix en León hacia el cambio de Era va a suponer la reorganización militar de todo el territorio astur (Morillo \& García Marcos, 2000: 598-600; Morillo, 2002: 77-81). El principal campamento de la Asturia Augustana debería enlazar necesariamente y en condiciones óptimas con el puerto astur mejor situado.

Por otra parte, el análisis de los materiales arqueológicos exhumados en las excavaciones del castro de Campa Torres apunta asimismo que la primera ocupación romana de este lugar ha de situarse en fechas muy próximas a la erección del monumento, concretamente en el periodo tardoaugusteo-tiberiano (Fernández Ochoa \& Morillo, 1994: 178).

Llegados a este punto cabe preguntarse si esta gran torre, elevada sobre uno de los puntos eminentes del Cantábrico, pudiera haber cumplido alguna otra función que la de mero hito conmemorativo. A comienzos del siglo $\mathrm{XX}$, Julio Somoza se planteo la cuestión en términos similares proponiendo finalmente, tal vez inspirado en Jovellanos, la probable existencia de un faro en este lugar ${ }^{24}$, sin que tal asunto fuese ni tan siquiera considerado en estudios posteriores.

Ahora bien, argumentada la presencia de una torre, de carácter sacro, conmemorativo y monumental en honor de Augusto, debemos abordar una última cuestión: su utilidad en el apoyo a la navegación, más concretamente como torre de señales o faro a la entrada de la rada gijonesa, cuestión ligada íntimamente a la importancia del puerto romano de este asentamiento (fig. 6). En efecto, la bahía de Gijón reúne las condiciones más favorables de cuantos fondeaderos se conocen en la accidentada y batida

\footnotetext{
${ }^{24}$ Somoza sin duda debió conocer el texto original de los Apuntamientos de Jovellanos, escritos en 1804 y que han permanecido inéditos casi hasta nuestros días (González Santos \& López, 2001: 19).
} 


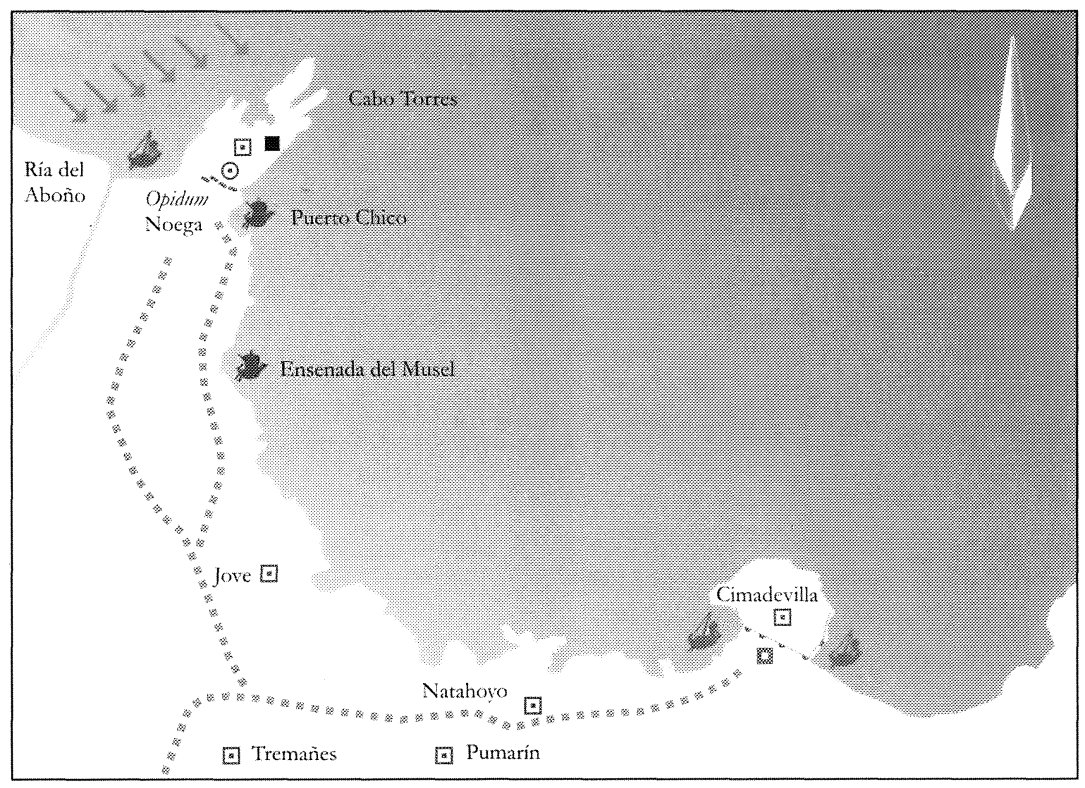

$\odot$ Castro prerromano ■ Asentamiento romano: villas y ciudad Salazones Faro romano de Torres

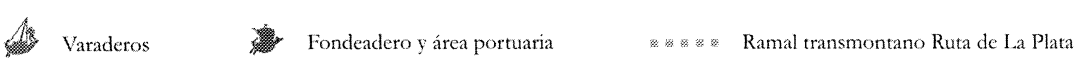

Fig. 7. Plano de la bahía de Gijón con localización de los topónimos citados.

costa de Asturias. En buena medida, esta cualidad es consecuencia de la proyección marítima del cabo hacia el noreste que, al abrigo de los vientos dominantes, origina hacia levante un cómodo surgidero. Las prestaciones del entorno de la punta de Torres como fondeadero natural nunca han sido cuestionadas, aceptándose su posición privilegiada como zona de atraque y desembarco durante la Antigüedad (Camino, 1995: 127). De hecho, el flanco oriental de mismo ha sido señalado recientemente por su calado y fácil acceso a tierra firme como probable zona portuaria en época romana (Fernández Ochoa et alii, 2003: 112) ${ }^{25}$ (fig. 7).

${ }^{25}$ Hacia la rada gijonesa el lugar idóneo no debió ser otro que el denominado Puerto Chico que aparece en el plano de Gijón de Pedro Texeira, quien en 1634, refiere lo siguiente: «...un ermoso cabo que llaman de Torre, donde dan fondo muchos navios de alto borde en quinze e bente braças, que dando seguros de los más dañosos bientos de esta costa que son poniente y norueste. Y siendo de enimigos con la misma seguridad salen a tierra a azer agua e leña ....». De su relato se concluye la vigencia aún en esta época del flanco oriental del cabo como refugio recomendable y, por consiguiente, de las instalaciones portuarias a las que se hace referencia en 1528 cuando las villas y puertos del Principado: «Piden se ponga en el puerto de Torres en Gijón medios de defensa (Cuartas, 1983: 140). Aún más, el cosmógrafo portugués señala las ventajosas prestaciones respecto al resto de puertos conocidos, entre los que se cuenta $-\mathrm{y}$ este hecho resulta de particular interés en nuestro discurso- el de Xixón, en un litoral que carecía de cualquier «... puerto considerable para armadas ny navíos gruesos, sólo para los que no llegan a demandar más que dos otrez braças de fondo y esto no se alla en todos sino en quatro, los más principales, que son: Llanes, Avilez, Xixón y Uillaviciosa». ¿Qué razón hay entonces para que las, aunque contadas, significativas alusiones al puerto de Gijón durante la Edad Media hayan sido sistemáticamente atribuidas al varadero de Cimadevilla y no al de Torres? (Ron, 2004: 62). Vistas las condiciones portuarias descritas en época moderna para Asturias y, en particular, para la bahía gijonesa parece razonable considerar que hubiese sido éste último y no otro el escenario de acontecimientos como el registrado en 1147 . En aquella fecha una flota de cruzados de hasta cincuenta buques procedentes de Inglaterra y con destino Lisboa, donde habrían de participar en su conquista aquel mismo año, arribaron al tiempo a un puerto de la región (Casariego, 1967: 202). Los dos relatos conocidos del suceso hacen mención al lugar de atraque con diferente denominación, Mala Rupis, uno y, Gollin, el otro. Es nuestra opinión que ambos debieran identificarse con el fondeadero de Torres, pues a su ventajosa, también exclusiva, disposición natural para dar cabida a semejante expedición, se suma el atributo «rupis» (rojizo), tal vez alusión ocasional y meramente descriptiva, al cromatismo encendido que caracteriza los acantilados del cabo. La omisión de estos términos en la documentación posterior y el toponímico regional avala el carácter circunstancial de su empleo, como lo fue la causa de arribada y accidental reunión -colligo/gollin-del comboy en esta costa.

El cruzado Osborne refiere en su crónica de viaje hacia la Expugnatione Olisiponis su llegada ad turrem Faris y las instalaciones portuarias de época romana aún visibles, señalando así las mismas escalas en su derrotero cantábrico que las indicadas en la Crónica de Alfonso III, en su versión A Sebastian, para los normandos que desde los mares del norte arribaron a las costas de Gijón antes de dirigirse hacia el Farum Bregantium (Somoza, 1908: 528). La reiteración en la 


\section{EL FARO ROMANO DE TORRES, UNA PROPUESTA PARA EL DEBATE}

La presencia de faros, construcciones turriformes estrechamente ligados al sistema de navegación romana (Reddé, 1979; Martínez Maganto, 1990), es tan necesaria o más en el ámbito atlántico que en el mediterráneo. Para responder mejor a las necesidades de las naves se emplazaban en eminencias del terreno junto a la entrada de puertos o estuarios, indicando un lugar de refugio seguro. A partir de los testimonios literarios son perfectamente conocidos los grandes faros de Alejandría -cuya construcción en el 280 a. C. por Sóstratos de Cnido en la isla de Pharos pasó a designar el tipo de edificio-, Ostia -donde Claudio elevó el faro sobre una isla artificial que protegía la entrada del puerto, surgida sobre los restos de una gigantesca nave hundida-, o Puteoli (Pozzuoli). Otros, como el de Leptis Magna, Brigantium (La Coruña) o Dubris (Dover) han podido ser documentados arqueológicamente. Pero han sobrevivido escasos restos constructivos de estos edificios, por lo que debemos recurrir a las representaciones iconográficas en moneda, pintura, mosaicos o relieve para reconstruir su fisonomía (Morillo, 2003: 29). Construidos en sillería u hormigón estas torres adoptan diversas formas. Podían constar de un solo cuerpo o de varios. Algunos combinaban varios cuerpos de plantas distintas. Rampas o escaleras daban acceso a los cuerpos superiores.

En el Arco Atlántico, restos constructivos de faros se han hallado en La Coruña (Hauschild, 1977: passim; Bello, 1991) y Dover (Wheeler, 1929; Philp, 1981). En ambos casos los edificios no son anteriores a los inicios del siglo II d. C. Aunque no ha llegado a nuestros días, el faro más antiguo en este ámbito sería el de la antigua Gesoriacum

ruta, transcurridos tres siglos de esta primera noticia, denuncia su utilidad como refugio y apoyo de cierta relevancia en la navegación por el Cantábrico, a pesar del paupérrimo desarrollo de sus infraestructuras portuarias que permite suponer la sistemática exclusión de Gijón en los fueros de mar hasta el siglo XIV, cuando se crea la Cofradía del gremio de mareantes de Santa Catalina (Somoza, 1908: 637). No obstante, nos inclinamos a pensar que su vigencia secular como puerto de refugio no se justifica exclusivamente por sus condiciones naturales óptimas, sino que además se vio favorecido por la pervivencia de un hito arquitectónico, la turris Augusti, cuya monumental entidad constructiva y privilegiada posición topográfica prolongó su protagonismo en el paisaje litoral incluso más allá de su abandono y ruina inicial. De hecho, su existencia encuentra inequívoco refrendo en el topónimo del cabo y la campa que lo antecede, redundante para mayor exactitud con la Fuente la Talaya donde Tirso de Avilés localiza las ruinas del edificio y que por testimonio de quienes visitaron el lugar y conocieron los restos en fechas inmediatas a su desaparición definitiva, se situaba sobre el área terminal del cabo (Maya \& Cuesta, 2001: 27).

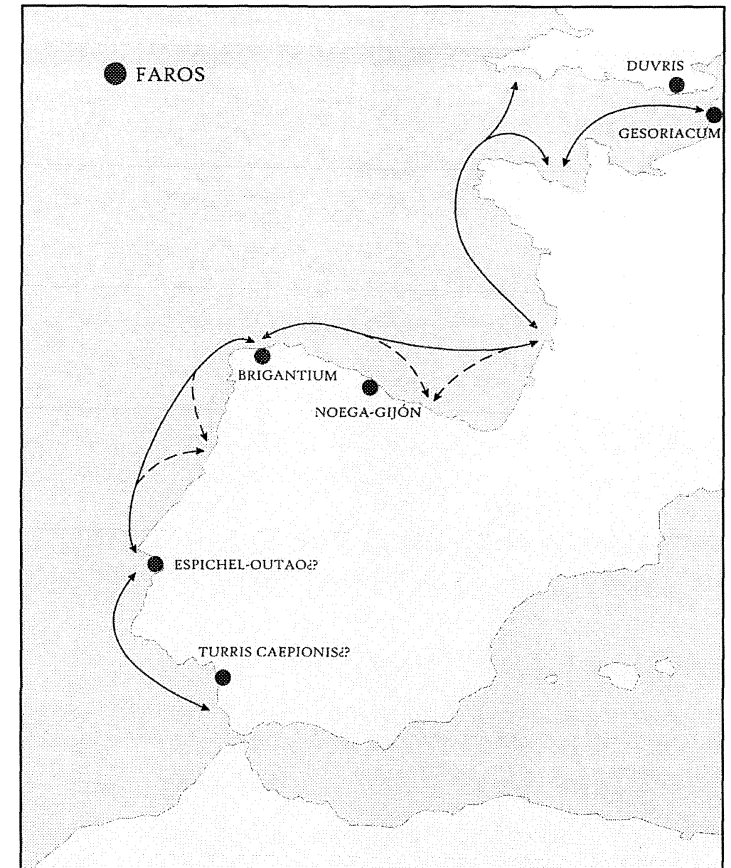

Fig. 8. Faros de época romana sobre la costa atlántica europea.

(Boulogne-sur-Mer), mandado hacer por Calígula ${ }^{26}$, que ha podido ser reconstruido gracias a las descripciones antiguas. Se disponía como una torre con varios cuerpos geométricos decrecientes, rematado de forma piramidal, que alcanzaba los $46 \mathrm{~m}$ de altura, y construido tal vez con una combinación de piedra y ladrillo (D’Erce, 1966; Reddé, 1979: 868). Dentro de este conjunto, y partiendo únicamente de la data de la inscripción augustea, el supuesto faro de Gijón sería el de cronología más antigua (fig. 8).

Navegando hacia el sur a lo largo de la costa occidental de la península ibérica, las fuentes clásicas señalan la presencia de un faro del siglo II a. C. en la desembocadura del Guadalquivir, turris Caepionis ${ }^{27}$ (Schulten, 1955, I: 149; Martínez Maganto, 1990: 82-83). Recientemente, Alarcão ha apuntado la posible existencia de una construcción del mismo tipo en el cabo Espichel, que protege la desembocadura del río Sado ${ }^{28}$.

${ }^{26}$ Suetonio, De vita doudecim Caesarum. Libri VIII: Caligula 46)

${ }^{27}$ Estrabón, Geog. III, 1, 9; Mela, Chor.III, 4.

${ }^{28}$ Esta interpretación se basa en la traducción del término pyrgos del relato estraboniano (III, 3, 1-3) como torre al borde del mar, esto es, faro (Alarcão, 2004: 317-322). Este mismo autor relaciona también con este posible faro la ciudad ptolemaica (Geographica II, 5, 5) de Pyrgoi Leukoi (Turres Albae), perteneciente a los célticos y situada en esta zona, que podría haber tomado su nombre de la presencia de dos 


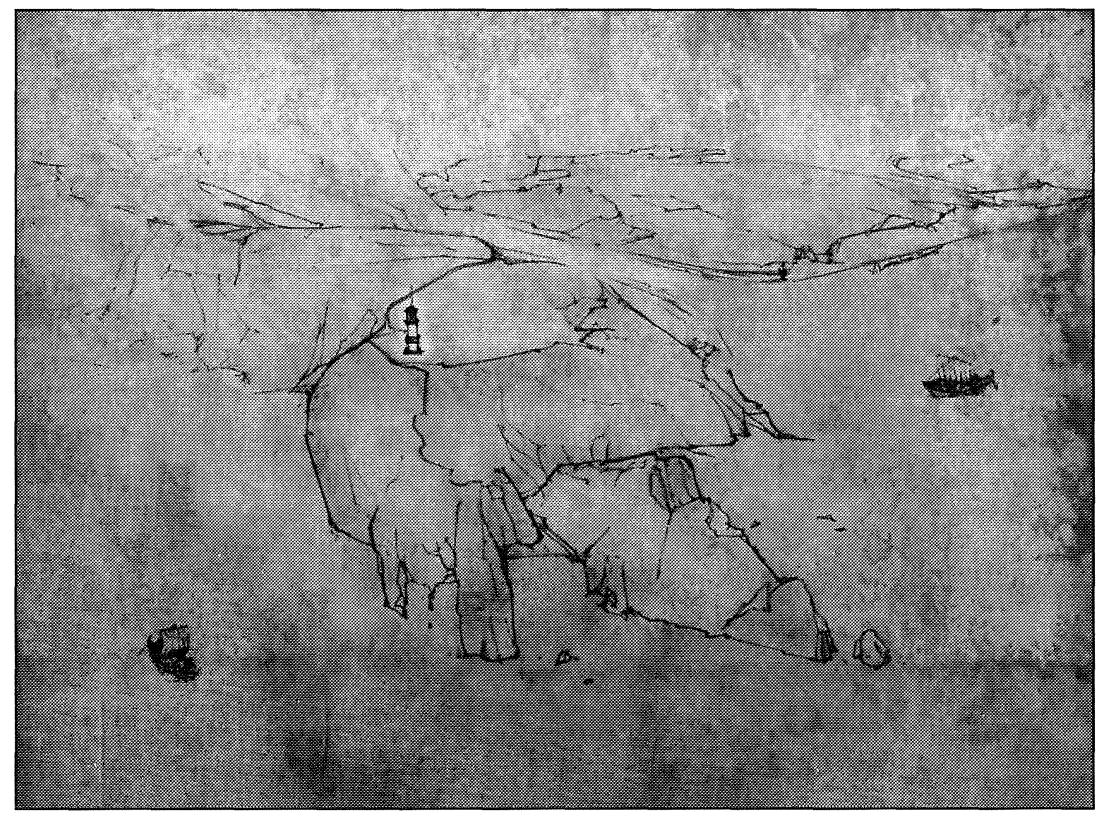

Fig. 9. Recreación del cabo Torres con el emplazamiento probable del faro romano. (Dibujo: Martín Vega Lorente).

La utilidad para navegantes de un edificio de carácter monumental como el propuesto para el cabo Torres, de perfil despejado y amplio dominio marítimo (fig. 9), es innegable aunque no necesariamente demuestra el uso del fuego como indicador. No obstante, la producción de señales luminosas durante la Antigüedad no siempre requirió de sofisticados mecanismos que condicionasen la morfología o aspecto de los edificios emisores. La columna trajana muestra lo rudimentario de alguna de estas torres en la que la señal se realiza mediante antorchas o tederos que asoman a través de los vanos superiores (Stevenson, 1959). Por otro lado, como bien se apunta en un trabajo reciente sobre el faro romano de A Coruña, con independencia de la existencia o no de luz que marque su posición en la oscuridad, durante el día la baliza de este tipo de monumentos seguía siendo igualmente efectiva (San Claudio, 2003: 131). En Torres concurren, además, el resto de circunstancias que caracterizan la localización del faro durante la Antigüedad como son su vinculación topográfica con el surgidero y su área portuaria, así como la proximidad al núcleo de población que lo generó.

torres construida con piedra blanca, tal vez faros. Una segunda torre pudo haberse situado en la fortaleza de Outão, donde aparecieron restos romanos interpretados como un templo a Neptuno (Alarcão, 2004: 318). Sin embargo esta hipótesis, que no está suficientemente desarrollada y resulta algo confusa, no ha sido constatada arqueológicamente, a pesar de que la península de la Arrabida ha sido prospectada de forma intensa.
En el estado actual de la investigación, todos los faros conocidos en el Atlántico presentan una estrecha vinculación con el ejército ${ }^{29}$. Algunos corresponden a puertos militares propiamente dichos, como los de las bases de la classis Britannica en Dubris y Gesoriacum. Otros se sitúan en un ámbito militarizado como el de Brigantium, que sin duda tuvo que tener una estrecha relación con el cercano campamento de A Cidadela. Para el caso del hipotético faro de Campa Torres, no debemos olvidar que protege el mejor fondeadero de toda la costa asturiana, que sin duda se convirtió en el acceso directo al campamento de la legio VI victrix en León y al resto de los campamentos romanos ubicados en territorio astur durante el periodo augusteo y tiberiano, momento que correspondería con la erección del faro. También en este caso nos encontramos en un ámbito que afecta a intereses básicos de la estrategia militar romana.

No resultaría extraño, dentro de este contexto, establecer una vinculación militar también para la lápida de Calpurnio Pisón. Uno de los paralelos más cercanos es una inscripción hallada en Bavay que conmemora una visita de Tiberio a la ciuitas romana de Bauacum durante el año 4 d. C. (CIL XIII, 3570) (fig. 10). Aunque dicho hallazgo carece de contexto arqueológico, en el CIL se señala que formaba parte de un gran monumento de culto impe-

${ }^{29}$ Dicha vinculación se manifiesta también en el Mediterráneo a través de faros como el de Ostia, Puteoli (Pozzuoli) o Forum Iulii (Frejus). 


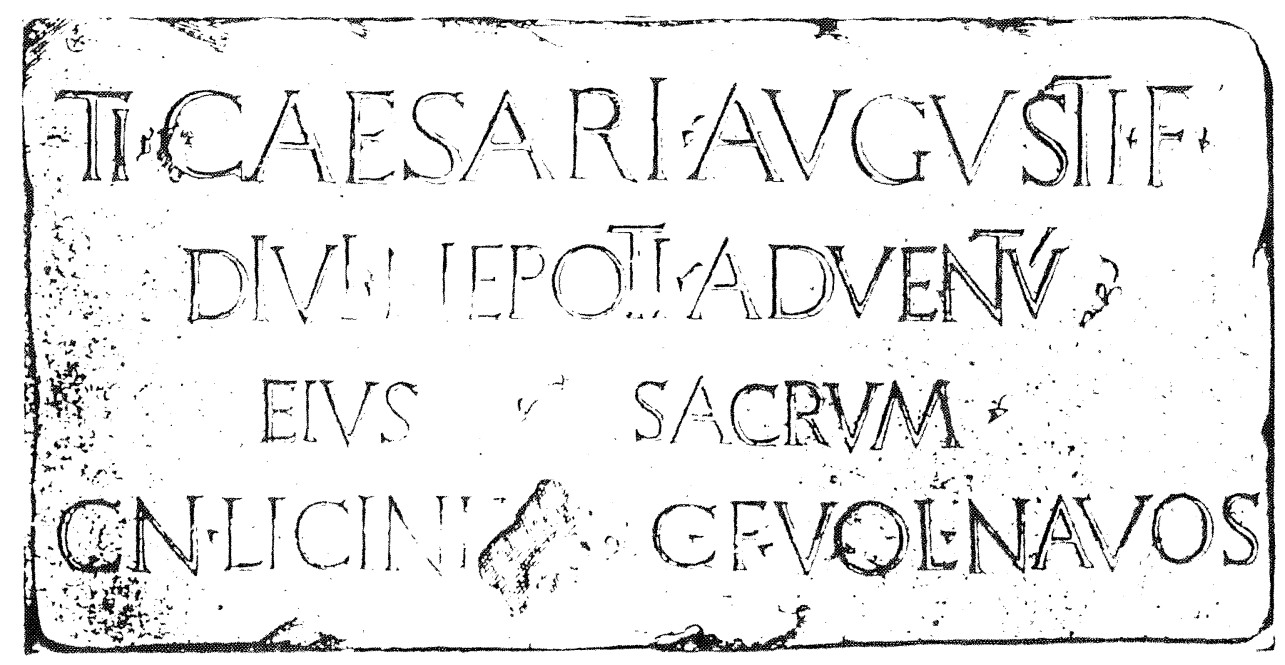

Fig. 10. Lápida consagrada a Tiberio procedente de Bavay (Musée de Bavay).

rial, al que pertenecían asimismo dos estatuas de mármol de Tiberio y Livia, todo ello reutilizado en la obra de la muralla tardía.

El paralelismo entre ambas inscripciones se fundamenta en varios aspectos que afectan por igual al contenido epigráfico como a su soporte, presentándose ambas sobre piezas sorprendentemente similares en material y tamaño. En el ámbito epigráfico las semejanzas se advierten por igual en el tipo de letra empleada, en la distribución del campo epigráfico sobre un único gran bloque de piedra y en el empleo de una fórmula de consagración genérica -sacrum-, sólo vinculada al nombre del emperador y su sucesor adoptado, pero no a divinidad alguna. Finalmente, una coincidencia más, tal vez la más significativa, subraya la similitud de ambas inscripciones, al tratarse de piezas labradas en la primera década de la Era (4 d.C., en el caso de Bavay; 9-10 d.C. en la Campa Torres).

Evidentemente, ambos documentos epigráficos manifiestan una consagración exclusivamente imperial, en un momento en que el culto al emperador se encuentra en un estado embrionario, y hallados en regiones militarizadas. La función de la antigua Bauacum y de la zona septentrional de la Galia en su conjunto, de cara al aprovisionamiento militar del limes germánico (Mertens, 1983), guarda interesantes paralelismos con la región astur transmontana en el periodo augusteo-tiberiano. Ya Etienne apuntó en su día el importante papel del ejército como instrumento de difusión del culto imperial, hecho que revistió una especial trascendencia en los territorios del noroeste peninsular (1974: 380-386), y en el conjunto de la Tarraconense, primera provincia en la que tenemos constatada la existencia de culto al emperador $\mathrm{Au}$ gusto antes de su muerte (Rodá, 2004: 419-420). Evidentemente, como señala Rodá, entroncando con las corrientes helenísticas pero sin ofender la tradición romana más genuina, Augusto se reviste de poder divino a la manera de un héroe, hijo de un dios, pero aún no divinizado. Las lápidas de Campa Torres y Bavay constituyen dos ejemplos paradigmáticos de la existencia de un culto imperial previo a la muerte de Augusto en el 14 d. C., así como de que el impulsor de las consignas oficiales en este terreno debió ser, en buena medida, el propio ejército.

\section{CONSIDERACIÓN FINAL}

A lo largo de estas páginas hemos intentado ofrecer una lectura arqueohistórica de las ruinas exhumadas en la península de Torres (Gijón) durante el siglo XVIII, a través de un análisis detenido de la abundante documentación historiográfica que se ha conservado, y que ha sido posible relacionar con la importante inscripción monumental de Calpurnio Pisón, datada en el 9/10 d. C. La conjunción de todos los datos disponibles nos ha permitido formular una hipótesis razonable sobre la existencia de una torre monumental consagrada a Augusto en el extremo del cabo Torres, dominando un amplio horizonte marítimo. Su caracterización como faro señalizador del mejor puerto astur, en una zona militarizada y recientemente conquistada, no sería improbable, si bien, como toda hipótesis, se encuentra sujeta a su comprobación arqueológica directa, difícil teniendo en cuenta la más que probable destrucción de gran 
parte de los restos durante la guerra civil. No obstante, debemos esperar a que futuras prospecciones de toda la superficie del yacimiento revelen si dicha destrucción fue total o todavía es posible recuperar alguna evidencia a partir de la interpretación que aquí hemos planteado.

\section{BIBLIOGRAFÍA}

ADAN, G. (1997): «Intervenciones arqueológicas de la Comisión Provincial de Monumentos Histórico-Artísticos de Oviedo (1844-1978)» Lancia 2, 207-233.

ADARO RUIZ, L. (1976): El puerto de Gijón y otros puertos asturianos, I, Gijón.

ALARCÃO, J. DE (2004): «Notas de arqueología, epigrafia e toponímia -I», Revista Portuguesa de Arqueología 7, 1, 317-342.

ALFÖLDY, G.; ABASCAL, J. M. Y CEBRIÁN, R. (2003): «Nuevos monumentos epigráficos del foro de Segobriga», ZPE 143, 255-274.

DE AVILÉS, T. (1965): Armas y linajes de Asturias y Antigüedades del Principado, ed. y notas de M. G. Martínez, Oviedo.

BELLO, J. M. (1991): «La investigación sobre la Torre de Hércules», Ciudad y Torre. Roma y la Ilustración en A Coruña, A Coruña, 165-170.

BONET CORREA (1971): Biografía de la villa y Puerto de Gijón, Gijón.

BOUBE, E. (1996): Le trophée augustéen, Collection du Musée Départamental de Saint-Bertrandde-Comminges 4, Saint-Bertrand-de-Comminges.

CARBALlO, L. A. (1685): Antigüedades y cosas memorables del Principado de Asturias, ed. facsímil, Gijón, 1984.

CAMINO MAYOR, J. (1995): Los castros marítimos en Asturias, Oviedo.

DE BLAS M. A. y GONZÁLEZ SANTOS, J. (1989): «Una carta del arquitecto Reguera sobre las ruinas de la Campa Torres en Gijón», Ástura, 7, 91-93.

D'ERCE, I. (1966): «La tour de Caligula à Boulogne sur mer», Revue Archéologie, 89-96.

ETIENNE, R. (1974) : Le culte impérial dans la péninsule iberique d'Auguste à Dioclétien, Paris.

FLÓREZ, E. (1759): España Sagrada XV, Madrid.

FERNÁNDEZ OCHOA, C. (1994): «Noega-Gigia: reflexiones sobre dos enclaves astur-romanos», Leyenda y Arqueología de las ciudades prerromanas de la península ibérica, Madrid, 53-60.

FERNÁNDEZ OCHOA, C. (1997): La muralla romana de Gijón, Gijón.

FERNÁNDEZ OCHOA, C. (2002) : «La ciudad ro- mana de Gijón (Asturias, España)», Espacios de ocio, convivencia y cultura en el Arco Atlántico. Los baños públicos como símbolo de la romanidad, Gijón, 29-48.

FERNÁNDEZ OCHOA, C. (2003): El lenguaje de las piedras. La recuperación del patrimonio arqueológico de Gijón (Asturias), Gijón.

FERNÁNDEZ OCHOA, C. y MORILLO, A. (1994): De Brigantium a Oiasso. Una aproximación al estudio de los enclaves marítimos cantábricos en época romana, Madrid.

FERNÁNDEZ OCHOA, C. y MORILLO, A. (2002): «El convento Araugustano y las Aras Sestianas: reflexiones sobre la primera organización administrativa del noroeste hispano», Latomus 61, 4, 889-910.

FERNÁNDEZ OCHOA, C.; GARCÍA DÍAZ, P. y GIL SENDINO, F. (2003): «Gijón, enclave marítimo en la ruta comercial cantábrica. Evidencias arqueológicas e hipótesis sobre el puerto romano y los embarcaderos antiguos», C. Fernández Ochoa (ed.) Gijón, puerto romano. Navegación y comercio en el Cantábrico durante la Antigüedad, Barcelona, 97-117.

ERA = DIEGO SANTOS, F. (1985, $2^{\mathrm{a}}$ ed.): Epigrafía Romana de Asturias, Oviedo

GARCÍA ARIAS, X. LL. (2000): Pueblos asturianos, el porqué de sus nombres, Gijón.

GIL SENDINO, F. y VILLA VALDÉS, A. (2005): «Circulación monetaria en Asturias durante los siglos I y II d.C. ¿Testimonio de asentamientos militares en zonas civiles?», M. P. García-Bellido (ed.), Abastecimiento de moneda al ejército romano, Madrid (en prensa).

GONZÁLEZ, J. M. (1979): «Pre-romano», El libro de Gijón, Gijón, 13-25.

GONZÁLEZ SANTOS, J. y LÓPEZ ÁLVAREZ, X. (2001): Gijón. Apuntamientos para el Diccionario Geográfico-Histórico de Asturias (Apuntamientos sobre Gijón, 1804), Gijón.

GROS, P. (2001): L'architecture romaine du début du IIIe siècle av. J.- C. à la fin du Haut Empire, 2. Maisons, palais, villas et tombeaux, Paris.

HAUSCHILD, TH. (1976): «Der Römische Leuchturm von La Coruña (Torre de Hércules). Probleme seiner Rekonstruktion, Madrider Mitteilungen 17, 233-258.

HAUSCHILD, TH. (1977): «El faro romano de La Coruña (Torre de Hércules). Problemas de su reconstrucción», Actas del Bimilenario de Lugo (1976), Lugo, 131-156.

LAMBOGLIA, N. (1983): Il trofeo di Augusto alla Turbia, Bordighera ( $4^{\mathrm{a}}$ ed.). 
LÓPEZ ÁLVAREZ, X. (1997): «El artículo «Gijón» de Jovellanos para el Diccionario Geográfico-Histórico de Asturias» en C. Fernández Ochoa: La muralla romana de Gijón, Gijón.

DE LA MADRID, V. (1995): La arquitectura de la Ilustración en Asturias. Manuel Reguera (17311798), Oviedo.

MARAÑÓN DE ESPINOSA, A. (1614): Historia eclesiástica de Asturias, ed. facsímil en Monumenta Historica Asturiensia III, Gijón, 1977.

MARTÍNEZ MAGANTO, J. (1990): «Faros y luces de señalización en la navegación antigua», $C u$ PAUAM 17, 67-89.

MAYA, J. L. (1998): «La Campa Torres (Gijón, Asturias) ¿oppidum Noega? Un ejemplo de urbanismo híbrido», Los orígenes de la ciudad en el Noroeste Hispánico. Actas del Congreso Internacional, II, Lugo, 945-978.

MAYA, J. L. Y CUESTA, F. (eds.) (2001): El castro de la Campa Torres. Periodo prerromano, Gijón.

MENÉNDEZ VALDÉS, G. (1785-1782) : Historia Antigua de Gijón I , (ed. L. Adaro Ruíz-Falcó,1986).

MERTENS, J. (1983): «The military origins of some Roman settlement in Belgium», Papers presented to $S$. Frere, Oxford, 155-168.

MORALES, A. de (1586): Crónica General de Espa$\tilde{n} a, I I I$ (ed. Gabriel Ramos Bejarano), Córdoba.

MORILLO, A. (2002): «Conquista y estrategia: el ejército romano durante el periodo augusteo y julio-claudio en la región septentrional de la península ibérica», A. Morillo (coord.), Arqueología Militar Romana en Hispania, Anejos Gladius 5, Madrid, 67-94.

MORILLO, A. (2003): «La navegación oceánica durante la época romana: de la imagen legendaria a la vertebración de un espacio marítimo atlántico», C. Fernández Ochoa (ed.) Gijón, puerto romano. Navegación y comercio en el Cantábrico durante la Antigüedad, Barcelona, 17-41.

MORILLO, A. Y GARCÍA MARCOS, V. (2000): «Nuevos testimonios acerca de las legiones $V I$ Victrix y $X$ Gemina en la región septentrional de la península ibérica», Deuxième congrès de Lyon sur l'armée romaine: Les legions de Rome sous le Haut-Empire (1998) Lyon, 589-607.

DE LA PEÑA SANTOS, A. (1990-91): «Consideraciones sobre las vías romanas de la provincia de Pontevedra», Castrelos III-IV, 217-243.

PHILP, B. (1981): The excavation of the Roman forts of the classis Britannica at Dover (19701977), Dover Castle, Kent.

PICARD, G. Ch. (1947): Thophées d'Auguste à Saint-Bertrand-de-Commingues, en Memoires de la Société Archéologique du Midi de la France 21, 5-52.

RATO Y ROCES, C. (1895): «Gijón», O. Bellmunt y F. Canella (eds.), Asturias, I, Gijón, (ed. facsímil, 1988), 131-186.

REDDÉ, M. (1979): «La représentation des phares a l'époque romaine», Melanges Ecole Française de Rome. Antiquite 91, 845-872.

RENDUELES LLANOS, E. (1867): Historia de la villa de Gijón desde los tiempos más remotos hasta nuestros días, Gijón, (ed. facsímil, 1985).

RISCO, M. (1789): España Sagrada, XXXVII, Madrid.

RODÁ, I. (2004): «El culto imperial y su reflejo en la colonia de Barcino», Divo Augusto. El descubrimiento de un templo romano en Croacia, Split, 418-423.

SAN CLAUDIO SANTA CRUZ, M. (2003): «El puerto de Brigantium y la navegación romana en el Atlántico Norte», en C. Fernández Ochoa (Ed.): Gijón puerto romano. Navegación y comercio en el Cantábrico durante la Antigüedad. Gijón, pp. 121-133.

SCHULTEN, A. (1943): Los cántabros y astures y su guerra con Roma, Madrid.

SCHULTEN, A. (1955): Fontes Hispaniae Antiquae, I, Barcelona.

SOMOZA, J. (1908): Gijón en la Historia General de Asturias, Vol. I, Gijón, (ed.facsimil, 1971).

STEVENSON, A. (1959): The world's lighthouse before 1820. Citado en SÁNCHEZ TERRY, M.A. (1991): Los faros españoles: historia y evolución, Ministerio de Obras Públicas y Transportes. Madríd, pág. 31.

SUÁREZ GARCÍA, J. A. (2003): «Aportaciones de la cartografía científica al conocimiento de la bahía de Gijón en la Antigüedad», C. Fernández Ochoa (ed.), Gijón, puerto romano. Navegación y comercio en el Cantábrico durante el Antigüedad, Barcelona, 72-96.

SYME, R. (1969): «A Governor of Tarraconensis», Epigraphische Studien 8, 125-133.

URÍA Y MENÉNDEZ VALDÉS, G. (1900): «Temas de Historia asturiana», O. Bellmunt y F. Canella (eds.): Asturias, tomo III, Oviedo, 489-504.

VILLA, A.; MENÉNDEZ, A. Y GIL, F. (2004): «Fortificaciones romanas en el castro de Chao Samartín (Grandas de Salime, Asturias)», Á. Morillo (ed.): Actas II Congreso de Arqueología Militar Romana en Hispania. Producción y abastecimiento en el ámbito militar, León (en prensa).

WHEELER, R. (1929): «The Roman light-house at Dover», Archaeological Journal LXXXVI, 2946. 